\title{
Genomic profiling and expression studies reveal both positive and negative activities for the Drosophila Myb-MuvB/dREAM complex in proliferating cells
}

\author{
Daphne Georlette, ${ }^{1}$ Soyeon Ahn, ${ }^{2}$ David M. MacAlpine, ${ }^{3,5}$ Evelyn Cheung, ${ }^{4}$ Peter W. Lewis, ${ }_{1}$ \\ Eileen L. Beall, ${ }^{1}$ Stephen P. Bell, ${ }^{3}$ Terry Speed, ${ }^{2}$ J. Robert Manak, ${ }^{4}$ and Michael R. Botchan ${ }^{1,6}$ \\ ${ }^{1}$ Department of Molecular and Cell Biology, University of California Berkeley, Berkeley, California 94720, USA; \\ ${ }^{2}$ Department of Statistics, University of California Berkeley, Berkeley, California 94720, USA; ${ }^{3}$ Department of Biology, \\ Massachusetts Institute of Technology, Cambridge, Massachusetts 02139, USA; ${ }^{4}$ Affymetrix, Inc., Affy \\ Laboratories-Transcriptome, Santa Clara, California 95051, USA
}

\begin{abstract}
Myb-MuvB (MMB)/dREAM is a nine-subunit complex first described in Drosophila as a repressor of transcription, dependent on E2F2 and the RBFs. Myb, an integral member of MMB, curiously plays no role in the silencing of the test genes previously analyzed. Moreover, Myb plays an activating role in DNA replication in Drosophila egg chamber follicle cells. The essential functions for Myb are executed as part of MMB. This duality of function lead to the hypothesis that MMB, which contains both known activator and repressor proteins, might function as part of a switching mechanism that is dependent on DNA sites and developmental context. Here, we used proliferating Drosophila Kc tissue culture cells to explore both the network of genes regulated by MMB (employing RNA interference and microarray expression analysis) and the genomic locations of MMB following chromatin immunoprecipitation (ChIP) and tiling array analysis. MMB occupied 3538 chromosomal sites and was promoter-proximal to $32 \%$ of Drosophila genes. MMB contains multiple DNA-binding factors, and the data highlighted the combinatorial way by which the complex was targeted and utilized for regulation. Interestingly, only a subset of chromatin-bound complexes repressed genes normally expressed in a wide range of developmental pathways. At many of these sites, E2F2 was critical for repression, whereas at other nonoverlapping sites, Myb was critical for repression. We also found sites where MMB was a positive regulator of transcript levels that included genes required for mitotic functions (G2/M), which may explain some of the chromosome instability phenotypes attributed to loss of Myb function in myb mutants.
\end{abstract}

[Keywords: Drosophila; Myb-MuvB/dREAM; transcription]

Supplemental material is available at http://www.genesdev.org.

Received August 1, 2007; revised version accepted September 19, 2007.

Metazoan chromosomes contain cis-acting elements called enhancers and silencers that regulate many nuclear functions of the cell including gene expression and DNA replication. Enhancers and silencers serve as binding sites for proteins that control the state of chromatin proximal to transcription start sites (TSS) or replication start sites by controlling the ability of the socalled core or basal factors to initiate RNA or DNA synthesis (Carey and Smale 2000; Levine and Tjian 2003).

\footnotetext{
${ }^{5}$ Present address: Department of Pharmacology and Cancer Biology, Duke University Medical Center, Durham, NC 27710, USA.

${ }^{6}$ Corresponding author.

E-MAIL mbotchan@berkeley.edu; FAX (510) 643-1729.

Article published online ahead of print. Article and publication data are

online at http://www.genesdev.org/cgi/doi/10.1101/gad.1600107.
}

These DNA modules thus serve as sites for processing information that define the epigenetic state of the cell (Ptashne 2007).

For purposes of classification, there are many examples of "modular enhancers" where the cis-acting elements are composed of clustered submotifs with flexible spacing between the DNA-binding sites that recruit different DNA-binding factors combinatorially. A model for such enhancer elements is the eve stripe 2 enhancer in Drosophila (Small et al. 1991). "Enhanceosomes" are another distinct type of enhancer element, where again, different DNA-binding factors are recruited to DNA. However, the exact spacing and geometry of the motifs are critical and when bound by proteins, allow for the creation of a higher-order nucleoprotein structure that is 
critical for enhancer function. The interferon- $\beta$ response element provides the paradigm for this type of enhancer where spatial differences of a single base pair can affect enhancer function (Thanos and Maniatis 1995a,b). For each of these enhancer types, the protein assembly may occur cooperatively but the path to building the functional site begins with individual DNA-binding factors. The discovery of complexes containing multiple sitespecific DNA-binding proteins such as Drosophila MybMuvB (MMB)/dREAM and tMAC (Korenjak et al. 2004; Lewis et al. 2004; Beall et al. 2007) suggest another model for assembly at enhancers and silencers. MMB contains DNA-binding proteins with both activating and repressing activities. It has been postulated that binding sites within silencers and enhancers might allow for a switch in function in a developmental pathway when bound by this complex (Beall et al. 2004, 2007; Lewis et al. 2004).

$\mathrm{MMB}$ is $\sim 700 \mathrm{kDa}$, and contains a unique ensemble of nine proteins, of which five are capable of binding to DNA: Myb, E2F2/DP, and Mip120 are site-specific DNA-binding factors, and a fifth protein, Mip130, contains an A-T hook domain capable of binding to AT-rich DNA. Although E2F2 and Myb have been widely studied individually, nothing has yet been explored as to how these DNA-binding proteins behave in an ensemble. Perhaps the more biologically relevant question is: How do the different site-specific DNA-binding proteins choose where to bind among the potentially large number of binding sites within the genome of a cell? It is likely that all or some combination of the DNA-binding activities may participate in $\mathrm{MMB}$ targeting to specific DNA sites. The other MMB factors-RBF1 or RBF2, Caf1/p55, Mip40, and Lin-52-are not known as DNA-binding proteins, but may contribute indirectly to DNA targeting through association with histones.

The Drosophila Myb protein can function as a transcriptional activator (Hou et al. 1997; Jackson et al. 2001; Okada et al. 2002; Lee and Orr-Weaver 2003). In addition, roles for $\mathrm{Myb}$ in the $\mathrm{G} 2 / \mathrm{M}$ transition and chromosome stability have been inferred from genetic studies of $m y b$ mutants (Katzen et al. 1985, 1998; Fung et al. 2002; Manak et al. 2002, 2007). The extent to which these roles for Myb are directly dependent on altered gene expression in the absence of Myb have not been resolved, in part, because Myb-dependent target genes have not been clearly identified. Myb is also required for DNA-mediated gene amplification in Drosophila follicle cells where $M M B$ functions as an activator through binding to the ACE-3 replication enhancer (Beall et al. 2002). MMB can also repress replication at other genomic sites, perhaps both directly and transcriptionally through limiting the levels of transcripts encoding for replication factors (Cayirlioglu et al. 2003; Beall et al. 2004, 2007). As all of the Myb protein is associated with MMB and the steadystate level (but not mRNA level) of Myb is dependent on Mip40, Mip120, and Mip130 (Beall et al. 2004; Korenjak et al. 2004; Lewis et al. 2004), a systematic study of the role for Myb in gene expression in terms of MMB association is needed.
E2F2 is also a stoichiometric component of MMB and E2F2 steady-state protein levels are similarly dependent on Mip120 and Mip130. The role of E2F2 in gene repression has been studied for the most part only in the context of association with the RBFs. Dimova et al. (2003) used RNA interference (RNAi) to deplete E2F2 and identified the set of genes requiring E2F2 for repression in Drosophila S2 cells. With the discovery of MMB/ dREAM, a number of genes in this list were chosen to assess the codependence for repression with the additional MMB factors. Initially, we and others showed that E2F2-dependent gene repression requires Mip120 and Mip130 but not Myb, even though Myb is found at these target gene promoters (Korenjak et al. 2004; Lewis et al. 2004). Importantly, the present literature defines MMB/ dREAM solely as a complex required for gene repression. We proposed that Myb is a silent partner for repression at these gene promoters, and might be involved in derepression or activation of these genes at a later point in development (Beall et al. 2004; Lewis et al. 2004).

myb loss is lethal in Drosophila, but such lethality is suppressed by loss of mip130, mip120, or mip40 (Beall et al. 2004, 2007). Furthermore, loss of mip40 or mip130 results in genome-wide DNA replication in amplification-stage follicle cell nuclei, establishing a repressive function for MMB in DNA replication (Beall et al. 2004, 2007). If one of the functions of Myb was to help induce genes already repressed by $M M B$, loss of $M y b$ might be lethal due to the inability to derepress an essential gene or set of genes. When both the repressing and activating functions of $\mathrm{MMB}$ are removed, severe phenotypes can result such as in the case of myb mip130 double mutants, which have shortened life spans (Beall et al. 2004). This is perhaps due to the inappropriate expression of many genes, but is less severe than loss of myb alone. One of the predictions of this model is that removal of Myb results in a partial MMB complex that is still targeted to a few vital gene(s). Furthermore, Myb would have an essential role in either derepression of $M M B$ and/or transcriptional activation of these vital genes. We showed recently that Myb targeting to polytene chromosomes is dependent on Mip120 and Mip130. Consistent with our model, Mip120 and Mip130 are still found on polytene chromosomes in myb mutant animals where some or all of the bound Mips may assume hypermorphic repressive activity (Beall et al. 2007). A more detailed view of the network of genes regulated by $\mathrm{MMB}$ and the sites within the genome bound by MMB are required to test this model more stringently.

All of the points raised thus far concern the mechanism(s) of targeting MMB to DNA, and highlight the importance of determining the actual sequences bound by $\mathrm{MMB}$ at such a resolution to enable further genetic testing of the cis-element requirements for MMB function. Moreover, deciphering the set(s) of genes regulated by MMB may help explain some of the observed phenotypes in animals mutant for members of MMB. To address these points, we targeted each of the MMB proteins using RNAi in Drosophila Kc tissue culture cells to assess the transcripts affected by removal of specific MMB 
subunits using microarray analysis. In addition, we performed a genome-wide analysis of the location of $\mathrm{Myb}$, E2F2, Mip130, Mip120, and Lin-52 in the same cell line. We found that MMB was bound to thousands of sites throughout the entire Drosophila genome. Interestingly, MMB was bound to far more sites than would have been predicted by the transcriptional profiling studies. Our data also indicated that targeting of MMB to DNA relied either on E2F2 or Myb, but generally not both. Unanticipated by previous observations, we found that Myb was involved in silencing at many sites where E2F2 was bound but not required for repression. Finally, a percentage of genes affected by the RNAi ablations required the MMB factors for normal levels of expression and had promoter-proximal binding sites for MMB. These data provide evidence that MMB can also participate in transcriptional activation.

\section{Results}

Long-term MMB depletion results in decreased growth rates and genome instability

To analyze the network of genes regulated by MMB, we first measured the kinetics of protein loss after targeting individual proteins of the complex by RNAi treatment. This kinetic analysis allowed us to determine the earliest time point for analyzing direct transcriptional effects of $\mathrm{MMB}$ member loss, while avoiding potential downstream secondary effects resulting from extended MMB member depletion. Loss of core factors can influence the accumulation of other MMB members in other cell lines and in vivo (Beall et al. 2004), and such data was needed for Kc cells.

RNAi targeting individual components of the complex (i.e., Mip40, Caf1/p55, Myb, Mip120, Mip130, E2F2, RBF2, and Lin-52) was achieved by adding doublestranded RNA (dsRNA) to Drosophila Kc cells. The efficiency of MMB subunit depletion was measured by immunoblot analysis (see Fig. 1A,B; Supplementary Fig. 1 for the quantification of the immunoblot data). After $4 \mathrm{~d}$ of treatment, levels of individually targeted MMB proteins were at least 10 -fold reduced, while no significant cell cycle progression defects were observed during this period (Fig. 1B). As reported for other cell types, Myb was the most affected by the loss of other complex members; its accumulation was significantly reduced in Mip130-, Mip120-, Caf1/p55-, and Mip40-depleted cells (Fig. 1A; Supplementary Fig. 1). Conversely, loss of Myb had no effect on the steady-state levels of the other factors. We also noticed that the accumulation of the transcriptional repressors RBF2 and E2F2 was dependent on the presence of other MMB members. In contrast, depletion of E2F2 only affected the abundance of RBF2. After RNAi targeting, Lin-52 levels were decreased with similar kinetics as the other MMB members, but it uniquely maintained a wild-type steady-state level in the absence of any other single MMB factor (data not shown). Targeting of Caf1/ p55, Mip120, and Mip130 led to the most significant decrease in the accumulation of other MMB members, and we refer to these three proteins as the "core" essential for the complex integrity. A schematic diagram illustrating the interdependence of each protein's steadystate levels after RNAi treatment is summarized in Figure $1 \mathrm{~A}$. As the Caf $1 / \mathrm{p} 55$ protein is also a component of other complexes active in these cells and involved in chromatin functions, we did not include this protein in our network analysis.

While cells treated with dsRNA targeting various MMB members could be maintained for serial passages, over time they proliferated more slowly than did the control samples (Fig. 1B). Analysis of these cells at late time points using FACS analysis revealed that loss of Myb resulted in an increase in the proportion of cells in G2/M while depletion of Mip120 and Mip130 caused an accumulation of the cells in G1 (Supplementary Fig. 2). The accumulated growth defects observed in the absence of MMB were also associated with chromosomal abnormalities. To document such abnormalities in more detail, cells were treated with demecolcine after $14 \mathrm{~d}$ of continuous RNAi treatment and analyzed for aberrant metaphase chromosomes. We found that depletion of Mip120, Mip130, or Myb led to genome instability (Fig. 1C). Three different chromosome classes were monitored: (1) wild type (tetraploid female karyotype) (Echalier 1997); (2) spreads where chromosomes exhibited impaired sister chromatid cohesion (ISSC), chromosome fragmentation $(\mathrm{F})$, and/or condensation defects $(\mathrm{CD})$; and (3) polyploidy (P) (Fig. 1C). For example, Myb-depleted cells exhibited up to a fourfold increase in the number of ISCC, F, and CD karyotypes, compared with control cells. These results corroborated previous in vivo data demonstrating that $\mathrm{Myb}$ is involved in genome stability (Katzen et al. 1998; Fung et al. 2002; Manak et al. 2002). It is interesting that myb-mutant larval brains show massive polyploidy (Manak et al. 2002), yet the Kc cells treated with dsRNA targeting Myb showed no such phenotype (Fig. 1C). Based on data presented below, we anticipated that cell type-specific chromosomal defects would be observed when MMB members were depleted following RNAi. We came to this view in light of the extensive network of genes regulated by the complex in Kc cells, the rather large number of MMB-binding sites found in the genome, and the recent finding that individual MMB members have different roles in different tissues (Beall et al. 2007). In conclusion, we chose to probe the gene expression network regulated by $\mathrm{MMB}$ after $93 \mathrm{~h}$ of RNAi treatment-a point at which Kc cells have significantly reduced target protein levels and very little overt cell cycle or genome stability phenotypes.

\section{$M M B$ factors repress and activate transcription of a wide range of developmentally regulated and cell-autonomous genes}

We combined the use of Affymetrix GeneChip Oligonucleotide arrays to monitor changes in gene expression following removal of the complex in Drosophila Kc cells, with Affymetrix GeneChip Drosophila Tiling arrays to determine MMB distribution across the entire genome. 
A RNAi to remove MMB $\downarrow$

Determine by immunoblot the effect of the absence of a specific MMB member on the abundance of other members:
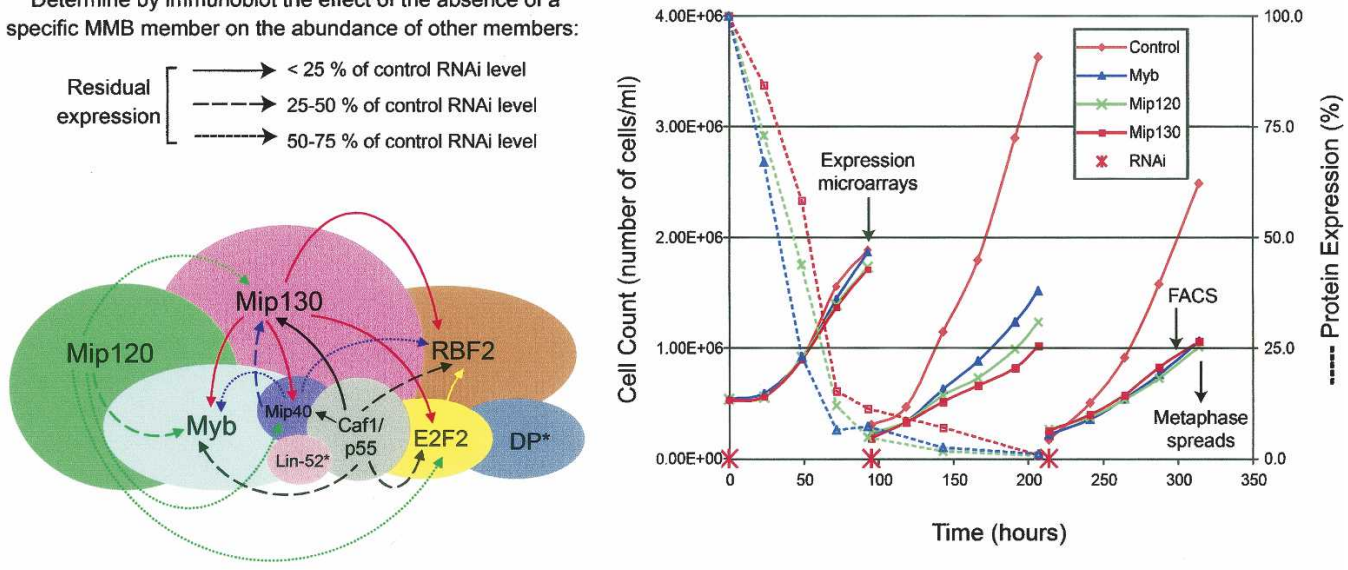

C

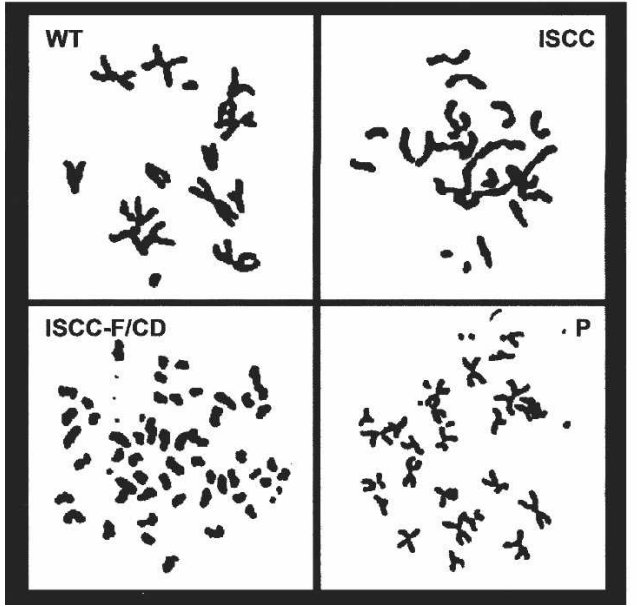

Figure 1. Cells depleted for $\mathrm{MMB}$ over a long period of time exhibit cell cycle progression defects and genome instability. (A) Accumulation of individual MMB complex members is dependent on multiple protein interactions. Shown is a schematic diagram of the accumulation of each protein after RNAi treatment. Arrow type depicts the amount that each protein was reduced in the absence of the indicated complex member, as follows: (solid) $<25 \%$ of control RNAi levels; (large dash) $25 \%-50 \%$ of control RNAi levels; (small dash) $50 \%-75 \%$ of control RNAi levels. Asterisks denote proteins for which the immunoblot quantification was not performed (Lin-52 and DP). (B) Kc cells were subjected to three consecutive RNAi treatments (over 14 d) to deplete MMB (Myb, Mip120, and Mip130, see inset), as denoted by red asterisks. RNAi with a nonspecific RNA derived from a $\mathrm{pBSK}^{+}$(named SK ${ }^{+}$was used as control. Cells were diluted at the end of each RNAi treatment into fresh media containing a new aliquot of dsRNA (the reason for the drop in cell count at each RNAi point). Cell growth (expressed as the number of cells per milliliter, solid line) and protein expression (dashed line) were monitored at specific time points. Times at which the samples were collected for microarray expression, FACS, and metaphase spread analyses are indicated by black arrows. $(C)$ MMB depletion results in the accumulation of abnormal chromosomes. Shown are representative metaphase spreads from Kc cells treated using RNAi for individual MMB members and stained with DAPI. Kc cells treated with SK-dsRNA were used as control. (Left panel) (WT) control metaphase spread exhibiting a normal tetraploid female karyotype; (ISCC) impaired sister chromatid cohesion; (F/CD) fragmentation/condensation defects; (P) polyploidy. (Right panel) Fifty metaphase spreads were counted after $14 \mathrm{~d}$ of RNAi treatment as described above (see inset for targeted protein) and analyzed for chromosomal defects (ISCC, F/CD, and P). The results are representative of three independent experiments. The most common abnormality was ISCC-F/CD for loss of Myb, Mip120, and Mip130, whereas those defects were less severe upon the loss of E2F2.

We performed RNAi against all individual MMB members except for Caf1/p55 and DP. It has to be noted that RBF1 and RBF2 were targeted as a pair (named RBFs) because of the apparent functional redundancy among the RBF proteins in tissue culture cells (Dimova et al.
2003). We also targeted the Drosophila lethal (3) malignant brain tumor protein, $\mathrm{L} / 3) \mathrm{MBT}$, as $\mathrm{L} / 3 / \mathrm{MBT}$ is substoichiometrically associated with $\mathrm{MMB}$ and required for repression of a number of genes targeted by E2F2 (Lewis et al. 2004). Association of L(3)MBT with MMB 
was confirmed by coimmunoprecipitation (Supplementary Fig. 3A). Although histones were not among the proteins copurifying with $\mathrm{MMB}$, we suggested that repression is aided, in part, by the contacts made between L(3)MBT and chromatin-bound histones (Lewis et al. 2004). In pull-down experiments, purified MBP-MBT repeats derived from L/3)MBT bound to core Drosophila histones, and specifically interacted with intact $\mathrm{H} 3$ and H4 tetramers (Supplementary Fig. 3B-D). Interestingly, Trojer et al. (2007) reported that a human homolog of L(3)MBT, L3MBTL1, is in a complex with core histones, $\mathrm{HP} 1 \gamma$ and Rb. Most significantly, they showed that L3MBTL1 can compact nucleosomes in a manner that is dependent on mono- or dimethylation of H4 Lys 20. The data shown in Supplementary Figure 3 imply that under our conditions, L/3|MBT showed affinity for essentially all of the H3-H4 tetramers present in 0- to 12-h Drosophila embryos and that specific targeting to defined genetic elements (see below) may be regulated by the site-specific binding of $\mathrm{MMB}$.

We found opposing effects on the mRNA levels of genes following RNAi targeting of MMB members: In the absence of $M M B$ members, many transcripts were up-regulated, extending the network of genes that $\mathrm{MMB}$ could repress, while others were down-regulated, showing that MMB played a role in activation. The statistical methods and experimental protocols used for analyzing the microarray data are described in the Materials and Methods. Given the large number of genes affected and the complexity of the data, we created classes wherein all genes in a given class required a common set of $\mathrm{MMB}$ factors. This approach is systematic but the choice of class definition was arbitrary. Venn diagrams (Fig. 2) and heat maps (Supplementary Figs. 4-7) were generated to help visualize the observed changes in gene expression when MMB members were removed. A complete list of the genes identified by our analysis as being regulated by MMB is provided in Supplementary Table 1 along with the relevant statistical data for each gene.

For brevity, we will describe the data for four classes termed A-D (Fig. 2; see below). These classes contain the core MMB factors and known DNA-binding proteins (i.e., Myb, Mip120, Mip130, and E2F2). Each of these classes (A-D) could be further subdivided according to the requirement for additional MMB members for class member expression [RBFs, Mip40, Lin-52, and L(3)MBT] (Fig. 2, pie charts). For example, Mip40 and L/3)MBT were required as corepressors for a significant number of genes $[61 \%, 76 \%$, and $51 \%$ for Mip 40 , and $66 \%, 79 \%$, and $60 \%$ for $\mathrm{L}(3) \mathrm{MBT}$ for Classes $\mathrm{A}, \mathrm{B}$, and $\mathrm{C}$, respectively] whereas Lin-52 was important for corepressing many Class $\mathrm{A}$ and $\mathrm{B}$ genes, but not for many Class $\mathrm{C}$ genes $156 \%, 66 \%$, and $17 \%$ in Classes $\mathrm{A}, \mathrm{B}$, and $\mathrm{C}$, respectively). Interestingly, we found that a fraction of the genes in the two classes that did not require E2F2 for repression still required the RBFs for repression $19 \%$ of Class C genes and $6 \%$ of the Class B genes), supporting the finding that Drosophila RBF2 can function independently of E2F2 (Stevaux et al. 2005). Based solely on sequence comparison, Mip130 may contain a domain for direct interaction with RBFs (Beall et al. 2007) and may be responsible for RBFs association in $\mathrm{MMB}$, in addition to E2F2.

The results of the gene expression microarray data were confirmed using Northern blot (Fig. 3) and quantitative PCR (qPCR) (data not shown) for $\sim 20$ genes representing each of the classes, A-D. We did not find any false positives from these analyses. For the Class A genes, elimination of E2F2, the RBFs, Mip120, or Mip130, but not Myb, led to dramatically increased transcript levels (Fig. 3A). Class A genes correspond to the previously described set of target genes discovered during the initial investigation of the transcriptional activities of MMB/dREAM, where Myb was not a critical component for repression (Korenjak et al. 2004; Lewis et al. 2004). For the Class B genes, Myb was needed for repression while removal of E2F2 or the RBFs had no effect on target gene expression (Fig. 3B). For the Class C genes, Mip120 and Mip130 without Myb or E2F2/RBFs were required for target gene repression (Fig. 3C). Finally, for the Class D genes, Myb, Mip120, and Mip130 were required for target gene activation because gene expression was decreased in their absence (Fig. 3D). The Northern blot data and qPCR also confirmed the requirements of Mip40, Lin-52, and L(3)MBT for MMB gene repression and activation (Fig. 3A-D). From these data, it is clear that $M M B$ can repress or activate a number of target genes in Kc cells, and that each member's contribution to MMB function is not coordinate.

The proteins encoded by the Class A genes are involved in diverse processes such as oogenesis (micr, Spn$E$, vasa), courtship behavior ( $q t c)$, and development (mesoderm: Myo31DF, how; larval/pupal: yellow-f2) (see Supplementary Table 1 for details). When comparing the list of the Class A genes to a list of known E2F2/RBFs targets in S2 cells (Dimova et al. 2003), we found a 45\% overlap between the two sets (see Supplementary Table 1). As for Class A, Class B genes encode proteins involved in diverse specialized programs such as germ cell development $(z p g)$, cell polarity (crb), and organization of actin filaments $($ Arpc $3 B)$. The 112 repressed transcripts within Class $\mathrm{C}$ are involved in important tissue and cell type-specific processes such as spermatogenesis (achi, vis, and nos), imaginal disc development (Idgf1), wing vein morphogenesis (tok), and RNAi (piwi) (Fig. 2A; Supplementary Table 1).

Similar to the wide range of gene functions requiring MMB for repression, the 49 Class D genes requiring MMB for activation are implicated in many specialized developmental programs (e.g., stai, sle, squ, and the FGF ligand bnl) (Supplementary Table 1). However, a significant fraction of these genes $(23 \%)$ encode proteins involved in the G2/M transition (Table 1). For instance, Klp61F, CENP-meta, Klp3A, and Pavarotti belong to a Kinesin superfamily that is thought to function as a molecular motor performing distinct roles during mitosis (Goshima and Vale 2003). Additional Class D genes contain a series of genes involved in chromosome condensation (ial), sister chromatid segregation (ial and pim), and completion of cytokinesis (ial, scra, and feo) (Table 


\section{REPRESSED}
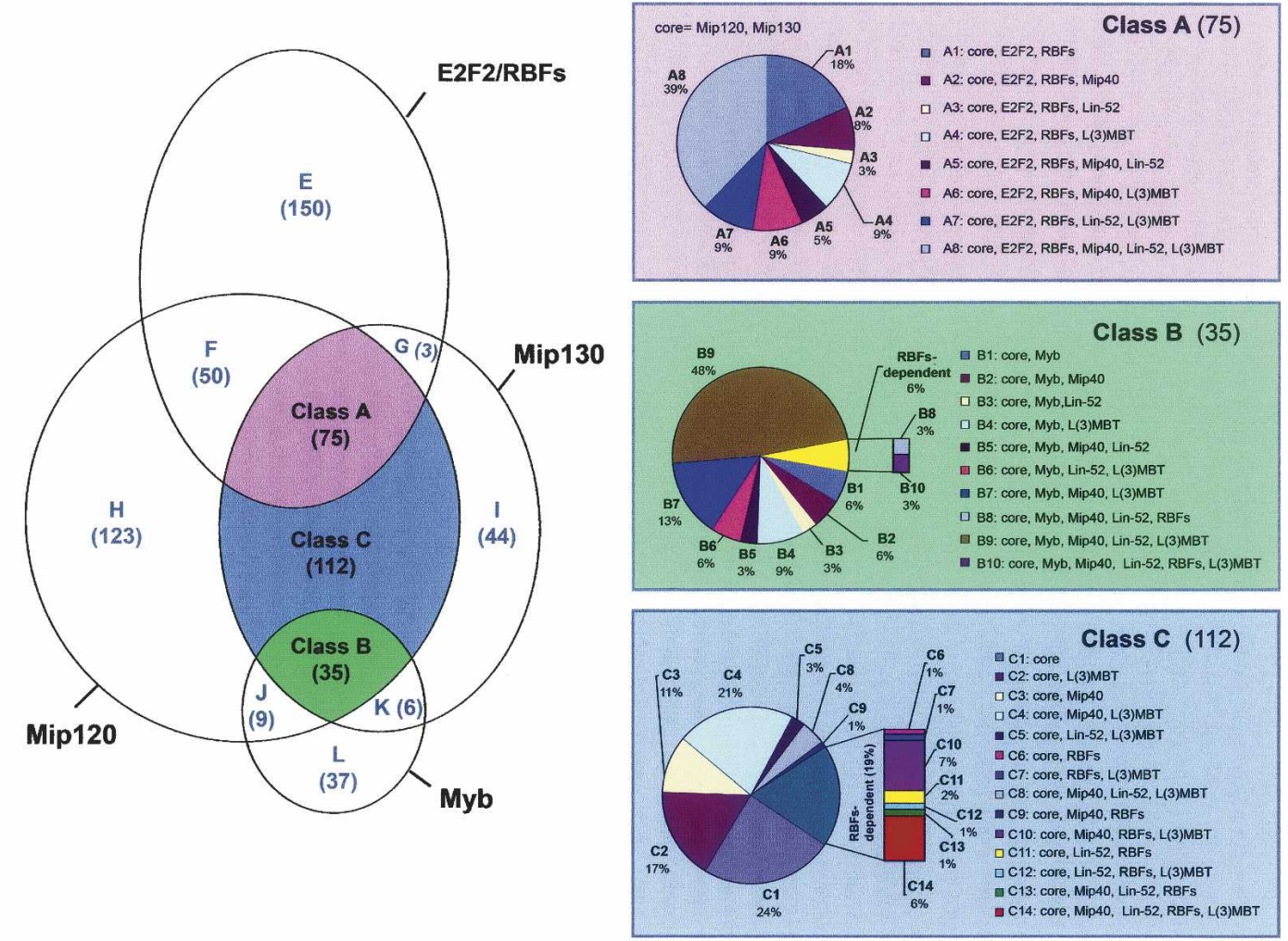

\section{ACTIVATED}
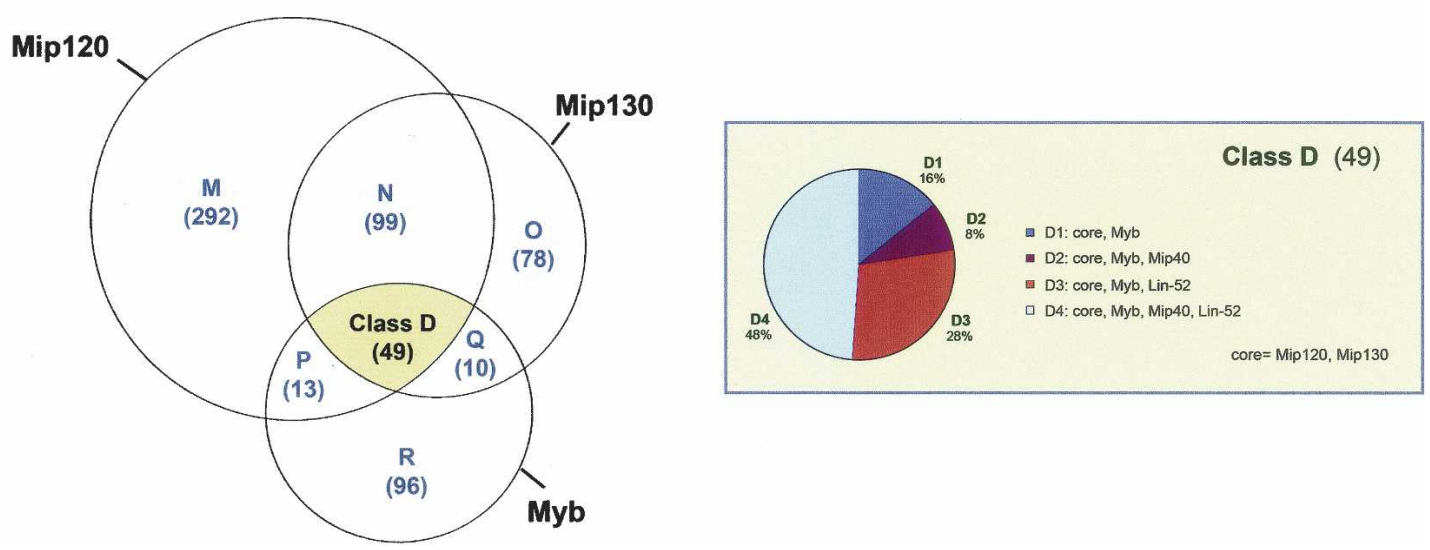

Figure 2. MMB represses or activates gene expression. (Top) Venn diagram showing the classes of genes repressed by MMB. Three classes of genes were thoroughly analyzed: genes repressed by the two core proteins (Mip120 and Mip130), E2F2, RBF1, and RBF2 (RBFs) but not Myb (Class A); genes repressed by the two core proteins (Mip120 and Mip130) and Myb but not E2F2 (Class B); and genes repressed by only Mip120 and Mip130 without either E2F2 or Myb (Class C). Each of these classes were further subdivided according to the requirement of the additional MMB members Mip40, Lin-52, both RBFs, and L(3)MBT (see pie charts on the right side of the figure). Numbers in parentheses refer to the number of genes found in each class. (Bottom) Venn diagram representing the classes of genes activated by MMB. The genes activated by Mip120, Mip130, and Myb belong to Class D. This class was further subdivided according to the requirement of the additional MMB members Mip40 and Lin-52 (see pie chart on the right side of the figure). A detailed list of all the genes regulated by MMB (A-R in the Venn diagrams) is given in Supplementary Table 1.

1). Interestingly, we found additional genes with known mitosis functions within the classes $\mathrm{M}, \mathrm{N}, \mathrm{P}, \mathrm{Q}$, and $\mathrm{R}$ (Table 1). Notable in this group are the genes Bub3, mei-
S332, Klp10A, mad2, and polo, all involved in chromosome dynamics during mitosis. Although the expression microarray data indicate that only one or two of the 


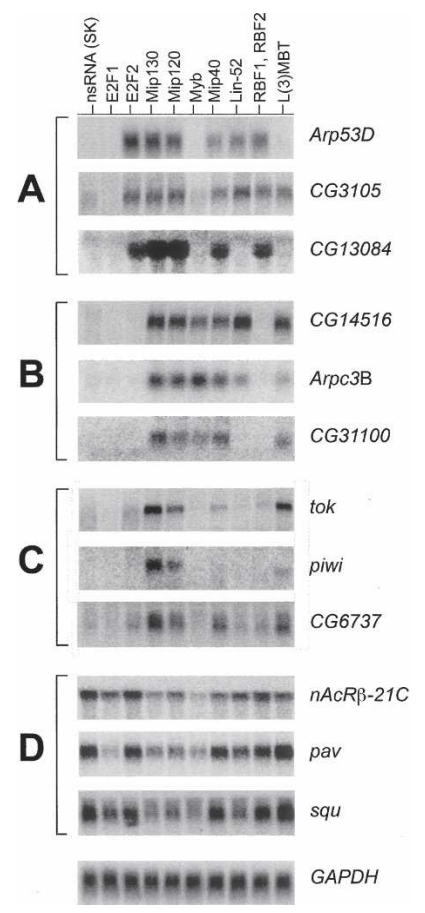

Figure 3. The MMB complex is involved in both transcriptional repression and activation. RNAi was used to specifically eliminate members of the MMB complex as indicated on the top. Total RNA was isolated from Kc cells treated with dsRNA for $4 \mathrm{~d}$ and analyzed by Northern blot for the abundance of the MMB-regulated transcripts using probes specific for the genes indicated on the right (Classes A to D). (nsRNA) Nonspecific RNAi (SK control). GADPH was used as a loading control (bottom).

MMB factors are required for normal levels of mRNA for these genes, in every case the complete set of MMB factors were localized close to the start sites for each gene (Table 1). In the absence of MMB, failure to appropriately activate any one or all of these different genes critical for G2/M transitions, could account, at least in part, for the chromosomal abnormalities observed in cells that were depleted of Myb, Mip120, and Mip130 over the extended period of time (Fig. 1C).

\section{$M M B$ is bound to thousands of sites} within the Drosophila genome

In order to map the genome-wide location of MMB in Drosophila Kc cells, we performed chromatin immunoprecipitations (ChIP) using antibodies against five $\mathrm{MMB}$ members (Myb, Mip120, Mip130, E2F2, and Lin-52). We identified the MMB-bound DNA sequences by hybridizing the immunoprecipitated material (as well as a control input DNA) to the newly developed GeneChip Drosophila Tiling 1.0R Array. This array contains $>3$ million probe pairs of 25 nucleotides (nt) in length, spanning the entire nonrepeat portion of the Drosophila genome (Manak et al. 2006). To identify DNA regions bound by $\mathrm{MMB}$, we first preprocessed the data using background correction and quantile normalization. After determining the probe level statistics and $q$-values (adjusted $P$ values) from the smoothed data, enriched regions ( $q$ value $<0.01$ ) and peak locations of the MMB members were defined. The statistical methods used for the analysis are described in Materials and Methods, and a complete list of all binding sites for each of the factors is given in Supplementary Table 2.

The ChIP-chip results showed that the entire set of MMB factors analyzed were colocalized to a total of 3538 sites located throughout the entire genome. A view of the distribution of binding sites along $\sim 2.5 \mathrm{Mb}$ of the $\mathrm{X}$ chromosome was a striking demonstration of this point (see Fig. 4A; Supplementary Fig. 8, where the data are presented before smoothing). Moreover, it was clear that the MMB-bound sites were clustered proximal to genedense regions and that the distribution of the bound genomic sites was located around promoter-proximal regions; thus, $86 \%$ of the MMB-bound regions were found within $1 \mathrm{~kb}$ of known or predicted TSS (Fig. 4B). We noted that the binding signals within the regions bound by all measured MMB members were not homogeneous. We arbitrarily defined a smoothed $\log 2$ ratio (lr) of the [ChIP signal/input] of $>2$ as a "strong" signal and a $7 r$ of $<0.5$ as "below detection." A signal between 0.5 and 2.0 was thus defined as "weak." Based on $1 r$ values for each MMB member analyzed, we created subfamilies (Fig. 4C). A complete graphical summary and table of the complexity for MMB member colocalization are provided in Figure 5.

Consistent with the very large number of binding sites and the many different functions of genes affected by MMB removal, we found no single family of genes that were located nearby the proximal binding sites of MMB. However, we were struck by the finding that many of the genes proximal to the MMB-binding sites showed no change in transcript levels following $\mathrm{MMB}$ targeting by RNAi. For example, a role for MMB in the regulation of genes important for S-phase progression in Kc cells was not supported by our microarray data (Class A-D genes). Nevertheless, we found a series of promoters of S-phase genes such as chif $(D b f 4)$, and the ORC and the MCM complex subunits that were bound by MMB (Supplementary Table 2). Interestingly, in follicle cells, these S-phase genes are actively repressed by E2F2 and RBF1 (Cayirlioglu et al. 2003). Cross-referencing the previously described transcriptional microarray data following RNAi and the actual MMB-binding sites as determined by ChIP-chip, we found that between $\sim 45 \%$ to $\sim 80 \%$ of the classes A-R were likely directly regulated by promoterproximal MMB (Supplementary Tables 2, 3). For example, we found that $\mathrm{MMB}$ was bound proximal to the TSS of $72 \%, 69 \%, 63 \%$, and $82 \%$ of Class A, B, C, and D genes, respectively. Substantiating a direct role for the complex in activating the expression of genes important for the G2/M transition, all five of the MMB proteins were detected at promoters for 28 of the 34 genes listed in Table 1.

Interestingly, we noticed correlations between the ChIP-chip signal strength and the requirement for either 
Table 1. List of MMB-regulated genes involved in cytokinesis and chromosome maintenance

\begin{tabular}{|c|c|c|c|c|c|c|}
\hline Class & Symbol & Name & $\begin{array}{l}\text { Human } \\
\text { homolog }\end{array}$ & $\begin{array}{l}\text { Northern/ } \\
\text { qRT-PCR }\end{array}$ & Function(s) & $\begin{array}{l}\text { Estimate for } \\
\text { peak binding } \\
\text { location }\end{array}$ \\
\hline $\mathrm{D}$ & cmet & CENP-meta & CENPE & $\mathrm{ND}^{\mathrm{a}}$ & $\begin{array}{l}\text { Metaphase chromosome } \\
\text { alignment }\end{array}$ & -358 to -797 \\
\hline $\mathrm{D}$ & СусB & Cyclin B & CCNB1 & ClassD & $\begin{array}{l}\mathrm{G} 2 / \mathrm{M} \text { transition of mitotic cell } \\
\text { cycle, cytokinesis }\end{array}$ & -286 to 175 \\
\hline $\mathrm{D}$ & feo & fascetto & $\mathrm{PRC1}$ & $\mathrm{ND}^{\mathrm{a}}$ & $\begin{array}{l}\text { Cytokinesis, mitotic spindle } \\
\text { stabilization }\end{array}$ & -460 to -748 \\
\hline $\mathrm{D}$ & ial & $\begin{array}{l}\text { IplI-aurora-like } \\
\text { kinase }\end{array}$ & AURKC & $\mathrm{ND}^{\mathrm{a}}$ & $\begin{array}{l}\text { Cytokinesis, mitotic sister } \\
\text { chromatid } \\
\text { segregation,mitotic } \\
\text { chromosome condensation }\end{array}$ & -257 to -397 \\
\hline $\mathrm{D}$ & Klp3A & $\begin{array}{l}\text { Kinesin-like } \\
\text { protein at 3A }\end{array}$ & KIF4 & $\mathrm{ND}^{\mathrm{a}}$ & $\begin{array}{l}\text { Metaphase chromosome } \\
\text { alignment }\end{array}$ & -37 to 262 \\
\hline $\mathrm{D}$ & Klp61F & $\begin{array}{l}\text { Kinesin-like } \\
\text { protein at } 61 \mathrm{~F}\end{array}$ & KIF11 & $\mathrm{ND}^{\mathrm{a}}$ & Proper bipolar spindle assembly & $\mathrm{NO}^{\mathrm{b}}$ \\
\hline $\mathrm{D}$ & Klp67A & $\begin{array}{l}\text { Kinesin-like } \\
\text { protein at } 67 \mathrm{~A}\end{array}$ & KIP3 & ClassD & Spindle assembly, cytokinesis & -114 to 469 \\
\hline $\mathrm{D}$ & pav & pavarotti & KIF23 & ClassD & $\begin{array}{l}\text { Formation and maintenance of } \\
\text { the central spindle, } \\
\text { cytokinesis }\end{array}$ & -128 to -160 \\
\hline $\mathrm{D}$ & pim & pimples & & ClassD & $\begin{array}{l}\text { Mitotic sister chromatid } \\
\text { segregation }\end{array}$ & 68 to 183 \\
\hline $\mathrm{D}$ & RacGAP50C & $\begin{array}{l}\text { Rac } \\
\text { GTPase-activating } \\
\text { protein } 1\end{array}$ & RACGAP1 & ClassD & $\begin{array}{l}\text { Formation and maintenance of } \\
\text { the central spindle, } \\
\text { cytokinesis }\end{array}$ & -57 to 393 \\
\hline $\mathrm{D}$ & scra & scraps & ANLN & $\mathrm{ND}^{\mathrm{a}}$ & Cytokinesis & 40 to 84 \\
\hline$M$ & Bap55 & $\begin{array}{l}\text { Brahma-associated } \\
\text { protein } 55 \mathrm{kD}\end{array}$ & ACTL6B & $\mathrm{ND}^{\mathrm{a}}$ & Cytokinesis & -130 to 46 \\
\hline M & Bub3 & Bub3 & BUB3 & $\mathrm{ND}^{\mathrm{a}}$ & Mitotic spindle checkpoint & -243 to 120 \\
\hline M & kst & karst & SPTBN5 & $\mathrm{ND}^{\mathrm{a}}$ & Mitotic spindle checkpoint & $\mathrm{NO}^{\mathrm{b}}$ \\
\hline M & mei-S332 & $\begin{array}{l}\text { Meiotic from via } \\
\text { Salaria } \\
332 \text { (Shugoshin) }\end{array}$ & Sgol/2 & $\mathrm{ND}^{1}$ & Sister chromatid cohesion & -598 to -749 \\
\hline M & ncd & $\begin{array}{l}\text { Non-claret } \\
\text { disjunctional }\end{array}$ & KIFC1 & $\mathrm{ND}^{\mathrm{a}}$ & Mitotic spindle elongation & 133 to 214 \\
\hline M & png & pan gu & & $\mathrm{ND}^{\mathrm{a}}$ & $\begin{array}{l}\text { Regulation of progression } \\
\text { through mitotic cell cycle }\end{array}$ & $\mathrm{NO}^{\mathrm{b}}$ \\
\hline $\begin{array}{l}M \\
M\end{array}$ & $\begin{array}{l}\text { Rpn9 } \\
\text { rho }\end{array}$ & $\begin{array}{l}\text { Rpn9 } \\
\text { rhomboid }\end{array}$ & PSMD13 & $\begin{array}{l}\mathrm{ND}^{\mathrm{a}} \\
\mathrm{ND}^{\mathrm{a}}\end{array}$ & $\begin{array}{l}\text { Regulation of exit from mitosis } \\
\text { Cytokinesis }\end{array}$ & $\begin{array}{l}221 \text { to } 572 \\
\text { NO }^{\text {b }}\end{array}$ \\
\hline $\mathrm{N}$ & barr & barren & BRRN1 & $\mathrm{ND}^{\mathrm{a}}$ & $\begin{array}{l}\text { Mitotic sister chromatid } \\
\text { segregation }\end{array}$ & -198 to -370 \\
\hline $\mathrm{N}$ & Cap-G & Cap-G & HCAP-G & $\mathrm{ND}^{\mathrm{a}}$ & $\begin{array}{l}\text { Mitotic sister chromatid } \\
\text { segregation, cytokinesis }\end{array}$ & 25 to 307 \\
\hline $\mathrm{N}$ & cnn & centrosomin & CDK5RAP2 & $\mathrm{ND}^{\mathrm{a}}$ & $\begin{array}{l}\text { Assembly of mitotic } \\
\text { centrosomes }\end{array}$ & 83 \\
\hline $\mathrm{N}$ & Gap1 & $\begin{array}{l}\text { GTPase-activating } \\
\text { protein } 1\end{array}$ & RASA3 & $\mathrm{ND}^{\mathrm{a}}$ & Sister chromatid cohesion & -577 to 168 \\
\hline $\mathrm{N}$ & $\mathrm{pbl}$ & pebble & ECT2 & $\mathrm{ND}^{\mathrm{a}}$ & Cytokinesis & -325 to 232 \\
\hline$P$ & Klp10A & Klp10A & KIF2 & $\mathrm{ND}^{\mathrm{a}}$ & $\begin{array}{l}\text { Mitotic sister chromatid } \\
\text { segregation }\end{array}$ & -36 to -123 \\
\hline $\mathrm{P}$ & CG16969 & Dgt2 & & $\mathrm{ND}^{\mathrm{a}}$ & $\begin{array}{l}\text { Localization of } \gamma \text {-tubulin to the } \\
\text { centrosome }\end{array}$ & $\mathrm{NO}^{\mathrm{b}}$ \\
\hline Q & aur & aurora & AURKA & $\mathrm{ND}^{\mathrm{a}}$ & $\begin{array}{l}\text { Mitotic centrosome separation, } \\
\text { centrosome cycle }\end{array}$ & -93 \\
\hline Q & $\operatorname{mad} 2$ & $\operatorname{mad} 2$ & MAD2L1 & $\mathrm{ND}^{\mathrm{a}}$ & $\begin{array}{l}\text { Mitotic spindle checkpoint, } \\
\text { chromosome segregation }\end{array}$ & -75 to -729 \\
\hline
\end{tabular}


Table 1. (Continued)

\begin{tabular}{|c|c|c|c|c|c|c|}
\hline Class & Symbol & Name & $\begin{array}{l}\text { Human } \\
\text { homolog }\end{array}$ & $\begin{array}{l}\text { Northern/ } \\
\text { qRT-PCR }\end{array}$ & Function(s) & $\begin{array}{c}\text { Estimate for } \\
\text { peak binding } \\
\text { location }\end{array}$ \\
\hline $\mathrm{R}$ & ald & Altered disjunction & TTK & $\mathrm{ND}^{\mathrm{a}}$ & Mitotic spindle checkpoint & 381 to 824 \\
\hline $\mathrm{R}$ & asp & Abnormal spindle & ASPM & $\mathrm{ND}^{\mathrm{a}}$ & $\begin{array}{l}\text { Microtubule cytoskeleton } \\
\text { organization and biogenesis }\end{array}$ & -291 \\
\hline $\mathrm{R}$ & CG3221 & Dgt3 & & $\mathrm{ND}^{\mathrm{a}}$ & $\begin{array}{l}\text { Localization of } \gamma \text {-tubulin to the } \\
\text { spindle }\end{array}$ & $\mathrm{NO}^{\mathrm{b}}$ \\
\hline $\mathrm{R}$ & Cks30A & $\begin{array}{l}\text { Cyclin-dependent } \\
\text { kinase subunit } \\
\text { 30A }\end{array}$ & CKS1B & $\mathrm{ND}^{\mathrm{a}}$ & Spindle assembly & -309 \\
\hline $\mathrm{R}$ & polo & polo & SLK & ClassD & $\begin{array}{l}\text { Chromosome alignment, } \\
\text { cytokinesis }\end{array}$ & -39 \\
\hline $\mathrm{R}$ & Sse & Separase & & $\mathrm{ND}^{\mathrm{a}}$ & $\begin{array}{l}\text { Mitotic sister chromatid } \\
\text { segregation }\end{array}$ & -253 to 60 \\
\hline
\end{tabular}

More than $20 \%$ of Class D genes encode for proteins involved in the G2/M transition. iHOP (http://www.ihop-net.org) and InParanoid (http://inparanoid.sbc.su.se/index.html) databases were used to find human homologs of the described genes. Northern blot and/or qRT-PCR were used to confirm the requirement of Myb, Mip120, and Mip130 in gene expression. The "Estimate for peak binding location" covers the region (minimum and maximum) bound by the entire MMB complex (Myb, Mip120, Mip130, E2F2, and Lin-52). a(ND) Not determined by Northern blot or qRT-PCR.

${ }^{b}$ (NO) No binding of the complex within $1 \mathrm{~kb}$ of the TSS of the gene of interest.

E2F2 or Myb for target gene regulation. For all of the Class A genes that required E2F2 but not Myb for repression, the Myb ChIP-chip signal was weaker than that of the other MMB members (Fig. 6A, top panel; Supplementary Fig. 9A). The distribution curves shown in Supplementary Figure 9A show the enrichment for each bound protein proximal to a TSS for each of the MMB factors analyzed via the ChIP tiling study, and we found that the E2F2 enrichment was approximately threefold stronger than the Myb signal. Conversely, the E2F2 signal was approximately threefold lower than the Myb signal in Class B and D genes where Myb was required for either repression or expression (Supplementary Fig. 9B,D; Fig. $6 \mathrm{~B}, \mathrm{D}$, top panel, respectively). In class $\mathrm{C}$, where neither E2F2 nor Myb were required for repression, the enrichment for E2F2 and Myb was similar (Fig. 6C, top panel; Supplementary Fig. 9C). Such binding biases were not reported previously because of the limited number of target sites analyzed. Prior to this study, we did not know that Myb was involved in gene repression through MMB or that E2F2 was located proximal to active genes. We performed qPCR at a few Class A-D promoters and confirmed the ChIP-chip data and more accurately measured the MMB enrichment at these sites (Fig. 6A-D, bottom panels). Consistent with the ChIP-chip signals, we found that at Class A promoters, there was a reduced Myb signal and similarly for E2F2 at Class B and D promoters. For both Myb and E2F2, the qPCR signals were fivefold to 10-fold above background demonstrating that Myb and E2F2 were still present at these promoters as part of MMB.

E2F2 and Myb behave as mutually exclusive targeting factors for $M M B$

The data described thus far suggest that E2F2 might be necessary but perhaps not sufficient for targeting $\mathrm{MMB}$ to Class A genes and that reciprocally Myb might be necessary but not sufficient for targeting MMB to Class $\mathrm{B}$ genes. In addition, E2F2 (for Class A) or Myb (for Class B) may have other essential roles for gene repression such as the recruitment of corepressors. To determine which $\mathrm{MMB}$ factors were required for targeting other MMB members to DNA, we used ChIP coupled with qPCR to analyze MMB binding to the promoter-proximal regions of two genes: qtc from Class A and CG31100 from Class B (Fig. 7). For each gene, we chose a series of primers to scan the promoter-proximal DNA to independently map the MMB-binding sites. For both genes, we found a peak for MMB binding that agreed well with the ChIP-chip data. DNase-1 footprinting further identified the specific bases bound by MMB for each gene (data not shown). Removal of E2F2 but not Myb led to a concomitant decrease in binding of Mip120 and Mip130 (and presumably MMB) to the qtc promoter (Fig. 7B, left panel) whereas removal of $\mathrm{Myb}$ but not E2F2 affected targeting of the complex to the CG3110 promoter (Fig. 7B, right panel). We detected a small but reproducible increase of the Myb enrichment upon loss of E2F2 at the qtc promoter and vice versa for E2F2 upon Myb ablation at the CG31100 promoter. Such phenomenon may indicate conformational changes in the complex upon loss of one or another factor, allowing for more efficient cross-linking of the remaining proteins to the DNA /see Discussion). The loss of E2F2 or Myb following RNAi did not affect the steady-state levels of either Mip120 or Mip130 (Fig. 1; Supplementary Fig. 1). Thus, the residual binding of Mip120 and Mip130 at the qtc and CG31100 promoters could be due to the independent DNA-binding activities exhibited by Mip120 and Mip130. Furthermore, the incomplete removal of E2F2 or Myb following RNAi treatment could also contribute to the low level of MMB still observed at these promoters. Nevertheless, we concluded that for Class A genes E2F2 clearly contributed to 
Figure 4. All five MMB members are colocalized throughout the Drosophila genome. DNA segments bound by MMB members were isolated using ChIP and identified using high-resolution tiling microarrays containing $>3$ million probe pairs of $25 \mathrm{nt}$ in length spanning the entire nonrepeat portion of the Drosophila genome (see Materials and Methods for details). (A) Illustration of the colocalization of the MMB members on a $2.5-\mathrm{Mb}$ portion of chromosome $\mathrm{X}$, as viewed in the Affymetrix Integrated Genome Browser (IGB, Affymetrix). Each vertical line shows the enrichment for the binding of the selected MMB member (Lin-52, pink; Mip130, red; Mip120, green; Myb, blue; and E2F2, yellow). The indicated annotations (white) are from RefSeq. Annotations above the chromosome $\mathrm{X}$ coordinates are transcribed left to right, and annotations below the coordinates are transcribed right to left. $(B)$ Distribution of the distance between bound probes and the closest TSS from Flybase (14,395 genes) for Myb (black), Mip120 (red), Mip130 (green), E2F2 (blue), and Lin-52 (turquoise). The null distribution of the distance between all probes and the closest TSS are shown as a black dotted line. $(C)$ Chart showing the percentage of regions bound by all MMB members (Myb, Mip120, Mip130, E2F2, and Lin-52), as well as by subclasses of MMB members (one to four MMB members). A detailed list of these different categories can be found in Supplementary Table 2. The class where all members are bound is subdivided into four subclasses based on the value of the $\operatorname{lr}_{\text {peaki }}$ i.e., the smoothed [ $\log 2$ ratio (ChIP sample/input)] (inset of the pie chart): $1 r_{\text {peak }}$ of all members $>2(i), 1 r_{\text {peak }}$ of all members $>2$ except Myb $\left(2>1 r_{\text {peak }}>0.5\right)\left(\right.$ ii), $1 r_{\text {peak }}$ of all members $>2$ except E2F2 $\left(2>1 r_{\text {peak }}>0.5\right)$ (iii), and other possibilities with $\left(2>1 r_{\text {peak }}\right.$ Myb and $\mathrm{E} 2 \mathrm{~F} 2>0.5)(\mathrm{iv})$.

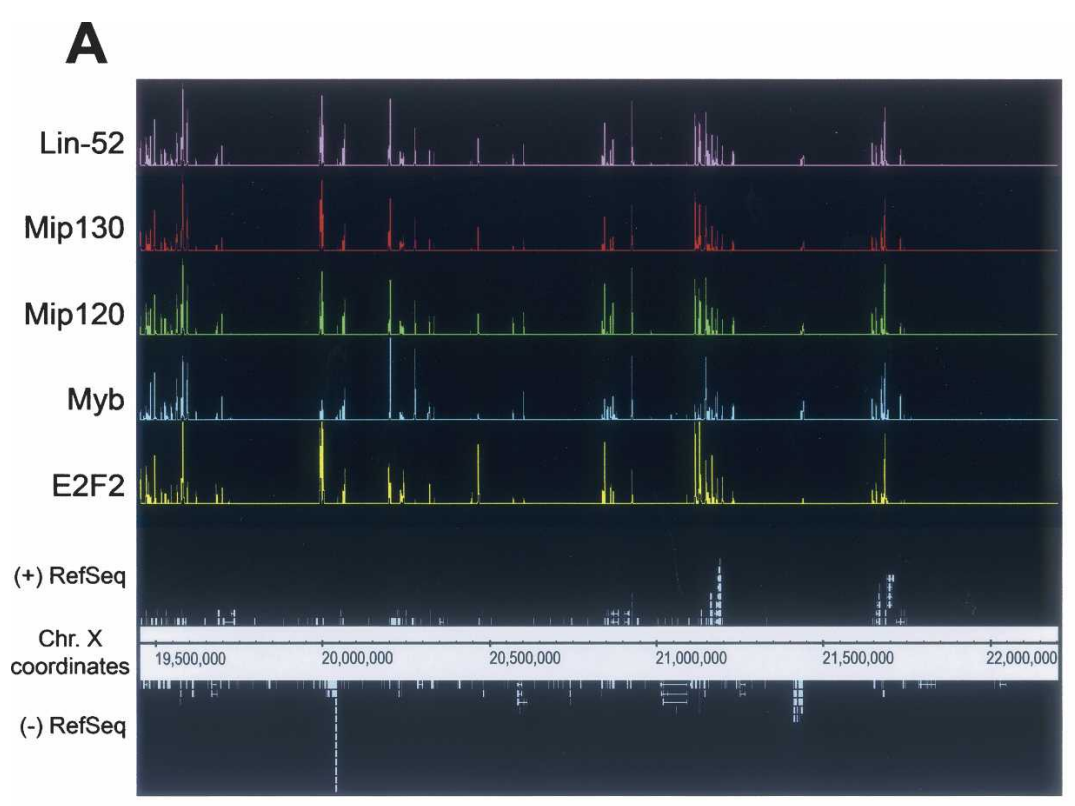

B

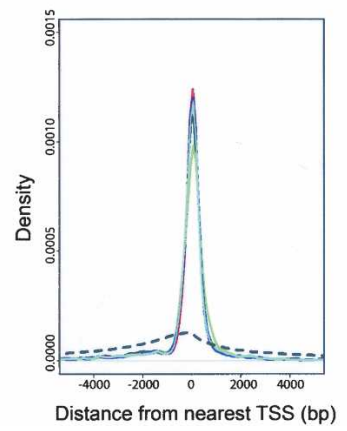

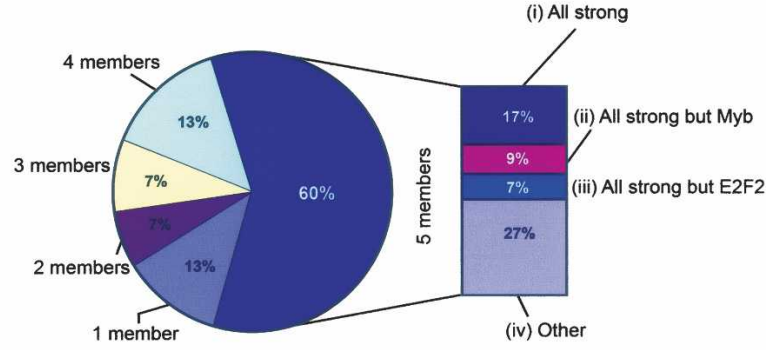

C

1 member
MMB targeting, and conversely, at Class B genes, Myb contributed to MMB targeting.

The differential requirement for E2F2 and Myb to target MMB to these promoters led us to ask if consensus DNA-binding sites for E2F2 (TTSSSSS) or Myb (YAACKG) were enriched at Class A and B gene promoters, respectively. Promoter regions spanning $1 \mathrm{~kb}$ upstream of each open reading frame that were bound by the entire $\mathrm{MMB}$ complex and strongly bound (i.e., $\operatorname{lr}_{\text {peak }}>2$ ) by E2F2 (Class A) and Myb (Class B) were analyzed using the motif search program MEME (Bailey and Elkan 1994). The conserved motif TTGGCGCGCAT TTT, which contains an E2F DNA-binding site, was found in $94 \%$ (45 out of 48 ) of the designated Class A promoters (Fig. 8; Supplementary Table 4), supporting the idea that E2F2 was important for targeting MMB at
Class A gene promoters. For the Class B promoters, $87 \%$ (26 out of 30) of the analyzed sequences were enriched for the CTGCAACTGG motif, which contains a Mybbinding site (Fig. 8; Supplementary Table 4).

We also analyzed the occurrence of all E2F (TTSSSSS) and $\mathrm{Myb}$ (YAACKG) consensus binding sites within $1 \mathrm{~kb}$ upstream of the 14,395 annotated genes in Flybase, and asked whether the derived consensus sequences were significantly enriched in the MMB-regulated promoters. As shown in Figure 8, the E2F-binding sequence was significantly enriched in the upstream region of the Class A genes than what was expected by chance ( $P$-value 0.007$)$. Furthermore, there was no evidence that the promoters of the Class B, C, and D genes were enriched for the E2F consensus sequence $(P$-values $0.5,0.1$, and 0.9 , respectively). In contrast, the Myb consensus sequence was 
Georlette et al.

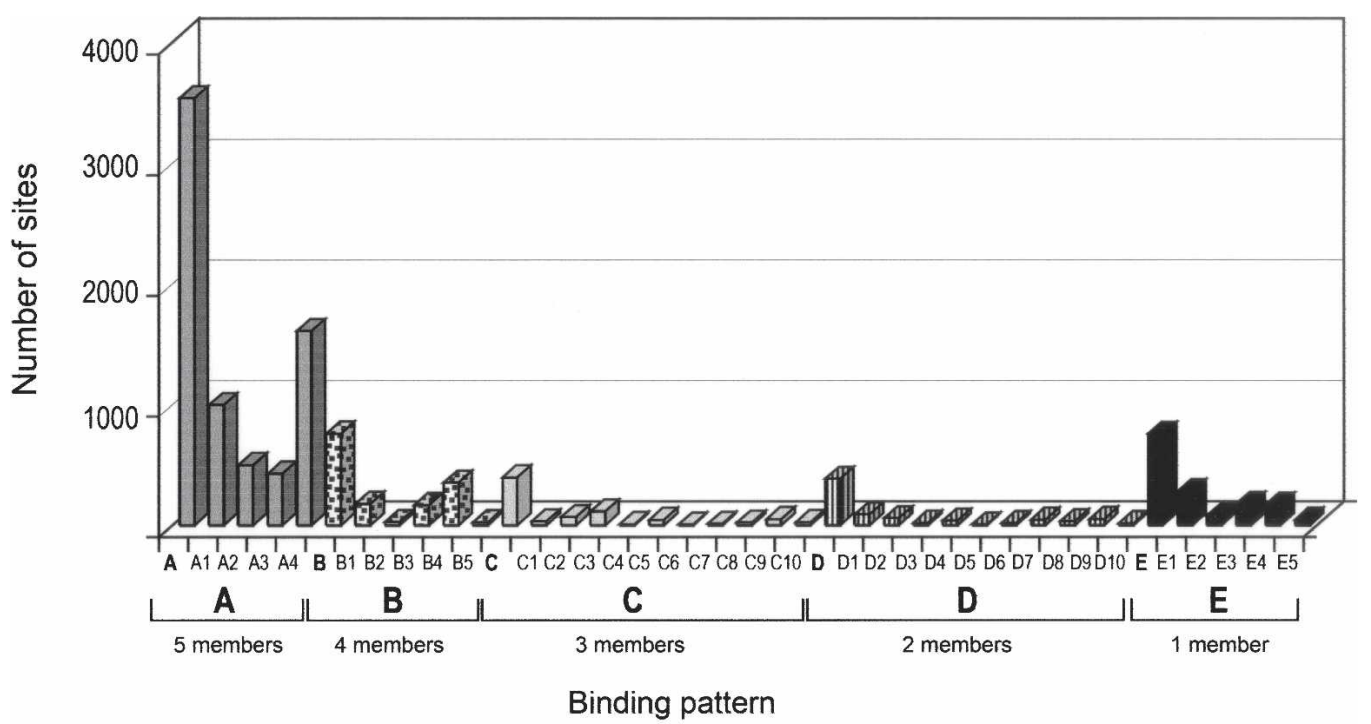

\begin{tabular}{|c|c|c|}
\hline Cat. & Binding pattern & Number of sites \\
\hline $\bar{A}$ & All five members bound (Mip120, Mip130, Lin52, Myb and E2F2) & 3538 \\
\hline $\mathrm{A}-1$ & All strong (Irpeak* $>2$ ) & 997 \\
\hline $\mathrm{A}-2$ & All strong (Irpeak > 2) except Myb $(2>$ Irpeak $>0.5)$ & 501 \\
\hline $\mathrm{A}-3$ & All strong (Irpeak $>2)$ except E2F2 $((2>$ Irpeak $>0.5)$ & 429 \\
\hline$A-4$ & Other with $(2>$ Irpeak Myb and E2F2 $>0.5)$ & 1611 \\
\hline B & Four members bound & 760 \\
\hline B-1 & 4 members bound: no binding of Myb & 180 \\
\hline B-2 & 4 members bound: no binding of Mip120 & 28 \\
\hline B-3 & 4 members bound: no binding of Mip130 & 170 \\
\hline B-4 & 4 members bound: no binding of E2F2 & 355 \\
\hline B-5 & 4 members bound: no binding of Lin- 52 & 27 \\
\hline C & Three members bound & 400 \\
\hline $\mathrm{C}-1$ & 3 members bound: Myb, Mip120, Mip130 & 33 \\
\hline $\mathrm{C}-2$ & 3 members bound: Myb, Mip120, E2F2 & 70 \\
\hline$C-3$ & 3 members bound: Myb, Mip 120 , Lin- 52 & 115 \\
\hline C-4 & 3 members bound: Myb, Mip130, E2F2 & 11 \\
\hline C-5 & 3 members bound: Myb, Mip130, Lin- 52 & 47 \\
\hline c-6 & 3 members bound: Myb, E2F2, Lin- 52 & 8 \\
\hline C-7 & 3 members bound: Mip120, Mip130, E2F2 & 14 \\
\hline C-8 & 3 members bound: Mip120, Mip130, Lin-52 & 23 \\
\hline C-9 & 3 members bound: Mip120, E2F2, Lin-52 & 52 \\
\hline$C-10$ & 3 members bound: Mip130, E2F2, Lin-52 & 27 \\
\hline D & Two members bound & 385 \\
\hline$D-1$ & 2 members bound: Myb, Mip120 & 89 \\
\hline $\mathrm{D}-2$ & 2 members bound: Myb, Mip130 & 60 \\
\hline D-3 & 2 members bound: Myb, E2F2 & 21 \\
\hline D-4 & 2 members bound: Myb, Lin- 52 & 39 \\
\hline D-5 & 2 members bound: Mip120, Mip130 & 9 \\
\hline D-6 & 2 members bound: Mip120, Lin-52 & 19 \\
\hline D-7 & 2 members bound: Mip120, E2F2 & 47 \\
\hline D-8 & 2 members bound: Mip130, Lin- 52 & 33 \\
\hline D-9 & 2 members bound: Mip130, E2F2 & 51 \\
\hline$D-10$ & 2 members bound: E2F2, Lin- 52 & 17 \\
\hline $\bar{E}$ & One member bound & 759 \\
\hline$E-1$ & 1 member bound: Myb & 282 \\
\hline $\mathrm{E}-2$ & 1 member bound: Mip120 & 81 \\
\hline$E-3$ & 1 member bound: Mip130 & 178 \\
\hline$E-4$ & 1 member bound: E2F2 & 171 \\
\hline$E-5$ & 1 member bound: Lin- 52 & 47. \\
\hline
\end{tabular}

Figure 5. MMB is primarily targeted to DNA as a complex. The main population of the regions called "bound" based on our statistics criteria are enriched for the entire MMB complex; i.e., Myb, Mip120, Mip130, E2F2, and Lin-52 (3538 sites, Category A). This class was subdivided into four subclasses based on the value of the $1 r_{\text {peaki }}$ i.e., the smoothed [ $\log 2$ ratio (ChIP sample/input)]: 997 sites where $1 r_{\text {peak }}$ of all members $>2$ (A1), 501 sites where $1 r_{\text {peak }}$ of all members $>2$ except Myb $\left(2>1 r_{\text {peak }}>0.5\right)$ (A2), 429 sites where $1 r_{\text {peak }}$ of all members $>2$ except E2F2 $\left(2>1 r_{\text {peak }}>0.5\right)(\mathrm{A} 3)$, and 1611 remaining sites (other) where $2>\operatorname{lr}_{\text {peak }}$ Myb and E2F2 $>0.5$ (A4). The number of sites bound by MMB subcomplexes was much smaller compared with that of sites bound by the entire complex (Categories B-E). This behavior was independent of the $q$-value used in the statistical analysis (see Supplementary Table 2 for details).

significantly enriched at the promoters of Class B genes $(P$-value 0.02$)$, while there was no evidence of such enrichment at the promoters of the Class $\mathrm{A}$ and $\mathrm{C}$ genes ( $P$-value 0.7 and 0.8 , respectively) (Fig. 8$)$. In addition, a
Myb consensus sequence was overrepresented in the upstream regions of the Class D genes (P-value 0.08) (Fig. 8). These data suggested that Myb was important for targeting MMB to both repressed (Class B) and activated (Class 
A
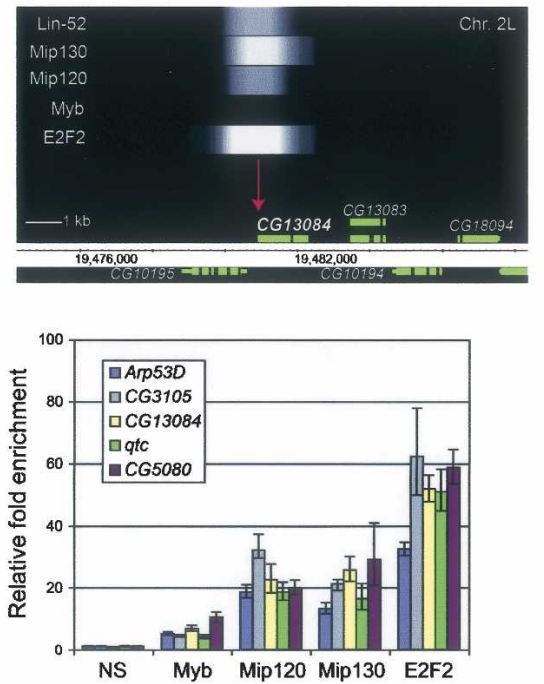

C
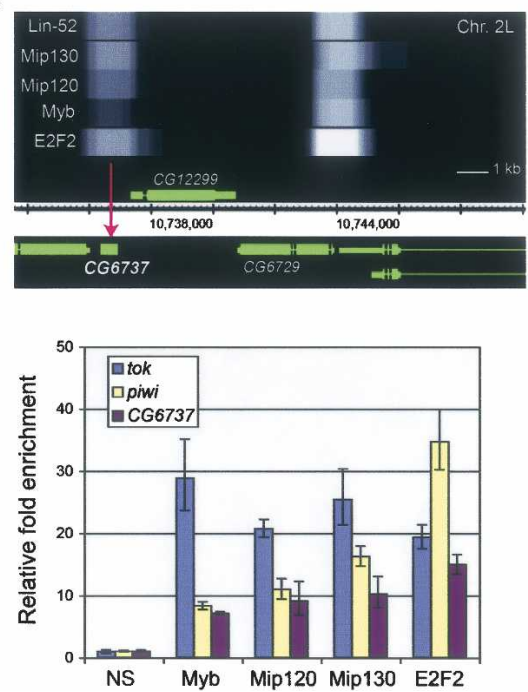

B
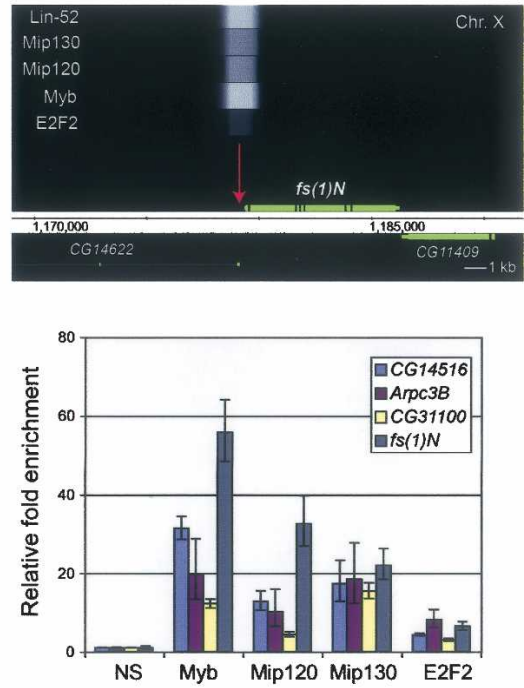

D
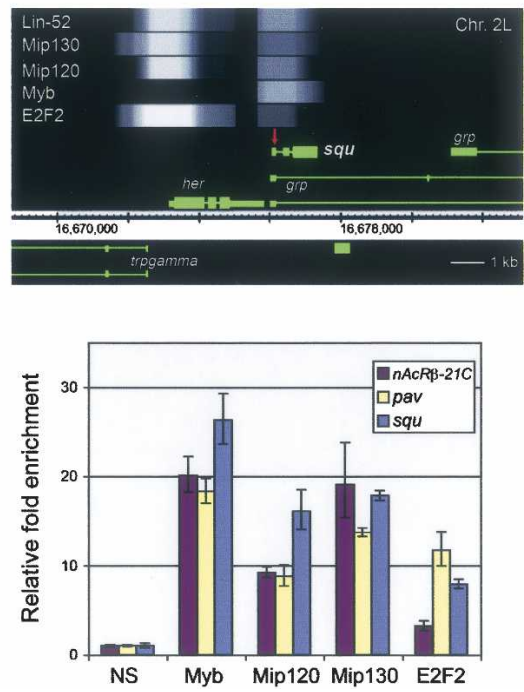

Figure 6. DNA binding by individual MMB subunits varies by the class of genes regulated by MMB. (Top) Shown are the locations of individual MMB subunits (Myb, Mip120, Mip130, E2F2, and Lin-52) for four representative MMB-regulated genes [the Class A gene $C G 13084(A)$; the Class B gene $f_{S}(1) N(B)$; the Class C gene CG6737 (C), and the Class D gene squ (CG4711) (D)], as viewed in the Affymetrix IGB following ChIP-chip analysis. The white signals show the location of enrichment for the MMB member indicated on the left. $(A-D$, bottom) ChIPs were performed using antibodies against members of the MMB complex, and the isolated DNA was analyzed by qPCR for the presence of promoter fragments derived from each class of the regulated genes. The relative fold enrichment for each ChIP was calculated by determining the ratio of intensities of the experimental regions to the actin promoter. For each promoter, the mock ChIP (NS) was normalized to a value of 1 (see Materials and Methods for details). The results are representative of three independent experiments.

D) promoters. Based on these findings, one would expect a correlation between the MMB-binding pattern and the DNA regions targeted by the complex. We indeed found that the MMB sites where all MMB members were strongly bound except for Myb were significantly enriched for the E2F consensus binding site ( $P$-value 0.001$)$, while the MMB sites where the E2F2-binding signal was weak were significantly enriched for the Myb consensus site (1E-13) (Fig. 8).

\section{Discussion}

Combinatorial requirements of individual $M M B$ factors for site-specific gene regulation

The major findings reported here revealed the extraordinary diversity of use and combinatorial requirements for the factors of the $\mathrm{MMB} / \mathrm{dREAM}$ complex in regulating gene expression. The Venn diagrams and subclasses for each set of genes regulated by MMB members shown in 
A
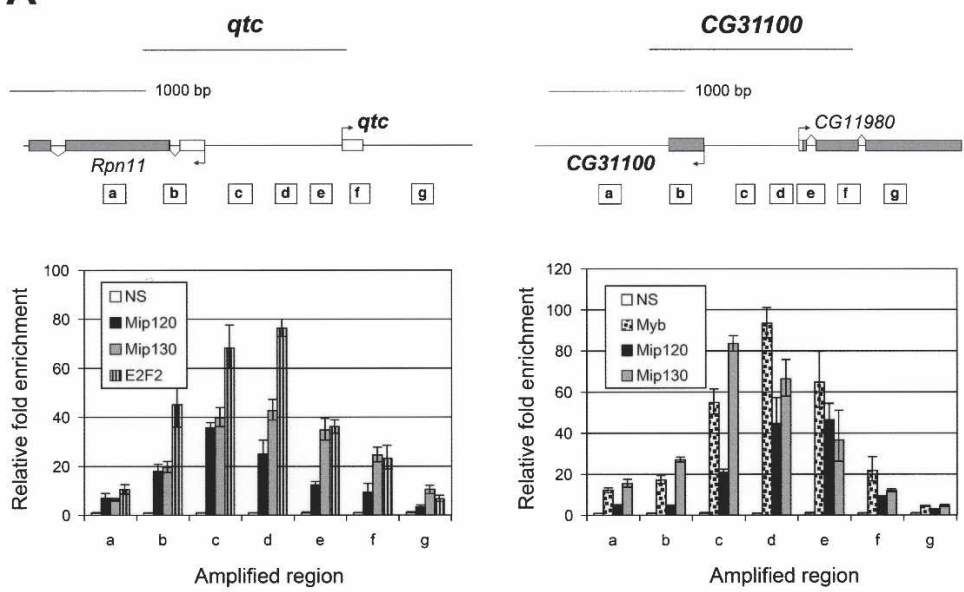

B
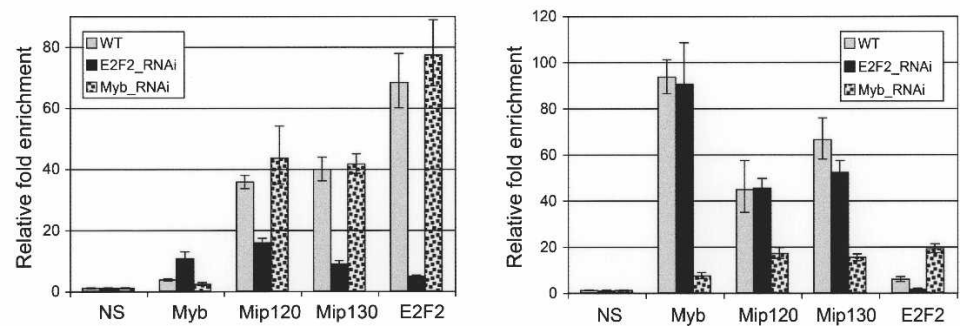

Figure 7. E2F2 and Myb behave as mutually exclusive targeting factors for MMB. (A) A single MMB complex regulates gene expression in Drosophila Kc cells. Graphical representations of the genomic region surrounding the Class A qtc (left) and Class B CG31100 (right) loci are on the top. The location of the qtc and CG3100 qPCR products, labeled a-g, are shown as boxes on the top. Black arrows indicate the start and direction of transcription. Histograms displaying the qPCR results following ChIP for the proteins indicated in each inset box are summarized at the bottom. The relative fold enrichment for each ChIP was calculated by determining the ratio of intensities of the experimental regions to the actin promoter following qPCR. The mock ChIP data (NS) was normalized to a value of 1 . Shown are the results and standard deviations for three independent experiments for each region. For both genes, the qPCR data were in agreement with the MMB location determined by ChIP-chip. (B) E2F2 and Myb are mutually exclusive for targeting MMB. ChIP was performed on chromatin isolated from E2F2- and Myb-depleted Kc cells following RNAi treatment using the antibodies against MMB members indicated on the bottom of each panel. qPCR was performed for the Class A qtc (left) and Class B CG31100 (right) promoters for the PCR products labeled " $\mathrm{d}$ " in each case. The relative fold enrichment for each ChIP was calculated by determining the ratio of intensities of the experimental regions to the actin promoter following qPCR. The mock ChIP data (NS) was normalized to a value of 1 . Shown are the results and standard deviations for three independent experiments. MMB association (as measured by Mip120 and Mip130 binding) was decreased at the $q t c$ promoter when E2F2 was removed (left) and at the CG31100 promoter when Myb was removed (right), demonstrating that E2F2 and Myb are indeed responsible for MMB targeting at Class A and Class B gene promoters, respectively.

Figure 2 illustrated this point for both the transcriptional repression and activation of gene expression by MMB. In the initial characterization of the complex, E2F2 and the RBFs but not Myb were found central for transcriptional repression (Korenjak et al. 2004; Lewis et al. 2004). A more complete description of the network of genes regulated by $\mathrm{MMB}$, and the genome-wide location of the individual $M M B$ members analyzed here revealed a more complex picture of the MMB regulatory network than previously thought. Some of this complexity may be the result of complexes containing subsets of individual MMB members. However, this scenario would not significantly change the present prospective. This is so because $>50 \%$ of all genes in each of our classes had proximal intact MMB complexes as determined by ChIP-chip analysis. For example, the genes listed in Table 1 involved in the G2/M transition and chromosome maintenance contained all five MMB members tested at sites proximal to the expressed gene, irrespective of the class into which the gene was classified by RNAi and microarray analysis.

Levels of Myb or E2F2 were dependent on Mip120 and Mip130 but not vice versa, and hence one would not anticipate classes of regulated genes to be dependent solely on Myb or E2F2. A number of confounding issues may contribute to this paradox, including incomplete RNAi and the possibility that partial complexes, arising after loss of a factor after ablation, may remain bound to a site (Beall et al. 2007). Such limitations might lead to misclassification of a certain gene(s). Focusing on Myb as an example, removal of Myb may critically limit regulation of a class of genes with different kinetics than would be observed following depletion of Mip120 or Mip130. Class Q is one such class for which the depletion of only Myb (and not any other MMB member) resulted in lowered transcript levels for Class Q members. One hypothesis is that RNAi treatment to remove either Mip120 or Mip130 resulted in incomplete loss of Mip120 and Mip130 such that just enough of the MMB complex remained targeted to such sites where MMB levels were sufficient to produce normal transcript levels for that gene. Our inference is that for such sites in the Q class, Myb loss would be most limiting.

Previous genetic and biochemical studies that linked the MMB members as one entity have been substantiated and extended by the data presented here. We found that the five MMB members tested (Myb, Mip120, Mip130, E2F2, and Lin-52) had strikingly coincident genomic binding site profiles (Figs. 4, 5). However, among the 3538 MMB-binding sites where the five proteins colocalized, there were significant differences in the enrichment signals (Figs. 5, 6). The observed variations in signal strengths at different sites for MMB members by ChIP-chip provided some intriguing correlations. For Class A repressed genes, the Myb ChIP-chip signal was lower than the ChIP-chip signal for E2F2, and this rela- 
tionship was reversed for the Class B repressed genes (Supplementary Fig. 9). There are many potential reasons for such differences in signal strengths including: different cofactor associations with MMB bound to a particular class of gene promoters, different subunit conformations/accessibility (resulting in altered pull-down antibody affinities), or perhaps because the formaldehyde cross-linking efficiency was highest for a protein that had a high affinity for a proximal DNA site. Moreover, MMB subunit composition in vivo may be dynamic, and off-rates for a DNA-binding factor may be lowest for those $\mathrm{MMB}$ factors that were tightly bound to a DNA site. Hence, for Class A genes that required E2F2 for repression, the cross-linking efficiency and potential targeting of E2F2 might dominate, whereas for Class B genes that required $\mathrm{Myb}$ for repression, the reverse would be found.

Consistent with this view, we found a statistically significant enrichment of Myb consensus binding sites nearby Class B genes and E2F2 consensus binding sites nearby Class A genes. We directly examined MMB targeting to one example for both Class $\mathrm{A}$ and Class $\mathrm{B}$ genes (Fig. 7), and for the Class A gene, E2F2 was critical for DNA binding whereas for the Class B gene, Myb was found to be a key targeting factor. Furthermore, for Class $C$ repressed genes, where neither E2F2 nor Myb were required for repression, equivalent ChIP-chip enrichment signals were found (Supplementary Fig. 9).

The genes repressed by MMB for both Class A and Class B were not cell cycle regulated and there was no biochemical evidence in Drosophila for the existence of two separate Myb- or E2F2-containing MMB complexes. Anti-Myb and anti-E2F2 antibodies coimmunopreciptated the entire set of MMB factors and hence each other. Furthermore, both E2F2 and Myb were stoichiometric in the defined complex-even after many different bio- chemical purification protocols of MMB (Lewis et al. 2004; Beall et al. 2007). We also tested this point in DNA binding experiments with purified $\mathrm{MMB}$ complex and biotinylated DNA fragments from either a Class A or B gene with a strong E2F2 site or strong Myb site, respectively. Regardless of the DNA fragment used in pulldown experiments, E2F2 and Myb stayed together (data not shown). We thus conclude that the complexity of both the targeting of MMB to DNA and the transcriptional function(s) of MMB are determined by DNA context and other proteins that may have associated with MMB. In this sense, MMB behaves like the multisubunit TFIID complex, where different TAF subunits determine DNA targeting at a specific promoter (e.g., $\mathrm{TAF}_{\mathrm{II}} 2$ at an Inr site; $\mathrm{TAF}_{\mathrm{II}} 6$ at a DPE site, and TBP at a TATA box) and the different TAF subunits interact with different coactivators (Hochheimer and Tjian 2003).

\section{$M M B$ plays a role in regulating genes important for $M$ phase}

Many genes required for the G2/M transition were regulated by MMB. Reduced levels for many of the genes listed in Table 1 could readily account for the chromosome phenotypes that were characterized after RNAi depletion of Myb, Mip120, or Mip130 including: impaired sister chromatid cohesion, chromosome fragmentation, and condensation defects. Furthermore, transcript levels for regulatory checkpoint genes involved in spindle assembly that might indirectly lead to chromosome instability were also affected by loss of MMB. In a recent study, Goshima et al. (2007) conducted a "genome-wide" RNAi screen to identify factors contributing to spindle assembly in Drosophila. Among the unexpected genes revealed by this screen were Myb, Mip130, Lin-52, Mip40, and Caf1/p55. We suggest that

Figure 8. Analysis of promoter regions bound by MMB for the enrichment of E2F and Myb DNA-binding sites. (A) The MEME program identified conserved E2F sites at the Class A promoters (left) and Myb sites at the Class B promoters (right). Motifs were constructed using WebLogo (http://weblogo. berkeley.edu). The height of a letter represents the relative frequency of occurrence. Exact locations of the regulatory motifs of the analyzed regions are given in Supplementary Table 4. (B) Analysis of the overrepresentation of E2F (TTSSSSS) and Myb (YAACKG) consensus binding sites among the promoters of genes bound by MMB. Flybase genes $(14,395)$ were scanned for both consensus sites within $1 \mathrm{~kb}$ upstream of their TSS, and the average occurrence of the studied motif was used as a population mean $(3.5$ and 1.7 for A

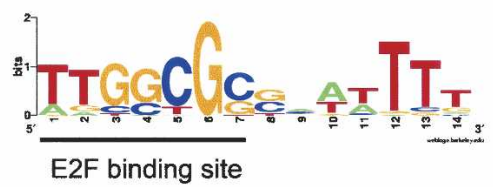

B

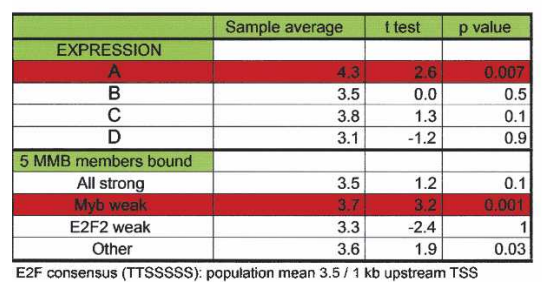

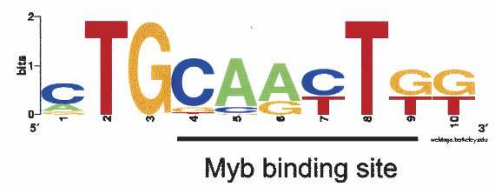

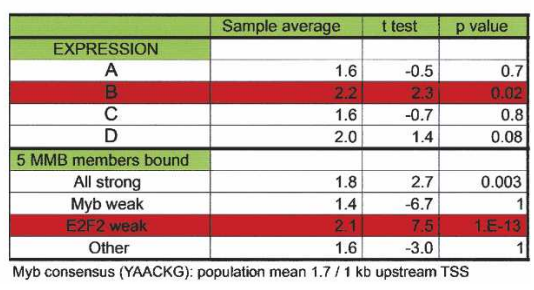

$\mathrm{E} 2 \mathrm{~F}$ and Myb sites, respectively). A one-sample $t$-test was run to ask whether the true average in the sample was higher than the population mean. Promoters of Class A genes are significantly enriched for E2F sites (left), whereas promoters of Class B and D genes are significantly enriched for Myb sites (right). Occurrence of E2F site is also higher at the promoters strongly bound by MMB, but Myb-while a Myb site-is overrepresented at the promoters strongly bound by MMB but E2F2 (see Materials and Methods for details). Data are given in Supplementary Table 4. 
the MMB member genes were identified in their study, at least in part, because MMB regulates the levels of other "expected" spindle assembly genes such as Klp61F (a kinesin) or Ial (Aurora-B kinase) or the "unexpected" spindle assembly genes such as RacGap50C-all of which are MMB-regulated Class D genes. It will be interesting to learn if the human homologs of MMB /Gagrica et al. 2004; Korenjak et al. 2004; Litovchick et al. 2007; Osterloh et al. 2007; Pilkinton et al. 2007) also regulate genes required for $\mathrm{G} 2 / \mathrm{M}$ in humans, because the oncogenic role of Myb in certain cell types may involve misregulation of spindle assembly genes that ensure normal karyotypes. We note that Ren et al. (2002) have shown that the human repressor E2F4 binds to genes involved in chromosomal stability, and one might suspect that this activity is functioning in the context of the paralogous human MMB/dREAM complex.

Many of the genes regulated by $\mathrm{MMB}$ and listed in Table 1 are essential, and in particular, the Class D genes are prominent in this regard. It is possible that the lethality observed for myb-null mutants is the result of misexpression of one or a set of these genes. However, even with a reduction of MMB factors $>95 \%$ after sustained RNAi treatment, we continued to see proliferation of Kc cells in culture. We point out that the transcript levels for genes requiring $\mathrm{MMB}$ for activation (Class D genes) were only modestly reduced (two- to fourfold) in the absence of MMB. Thus, the regulation of these genes by Myb may not be profound or responsible for the lethality of myb mutations in flies. Nevertheless, there are reasons to suspect that the regulation by $\mathrm{MMB}$ of these target genes may be relevant at least in part to the essential requirements for Myb in vivo. Recall that myb-mutant lethality is suppressed by loss of mip40, mip120, or mip130 (Beall et al. 2004, 2007). Following along the lines of our model derived from these genetic studies one might suggest that the critical regulatory step dependent on Myb involves derepression from a quiescent state where cells need to switch on such essential genes for mitotic functions. Such a switching mechanism may be nonessential in cell culture. Hence, repression in a quiescent cell in the developing fly, perhaps mediated by Mip120 and Mip130, may require Myb for induction at a later time or in a specific tissue. In vivo, but not in cell culture, loss of Myb alone (as in mybnull mutants) could result in a "permanently repressed" essential gene whereas loss of the entire MMB complex (as in myb; mip120 mutants) may allow for suboptimal expression levels of an essential gene(s); for instance, at a two- to fourfold reduced level. Thus, a presently scored Class D gene may behave as a Class $\mathrm{C}$ repressed gene in another cell type, where loss of $\mathrm{Myb}$ would leave a repressive $\mathrm{MMB}$ complex that is unable to be induced.

One important issue that needs to be explored is how $\mathrm{MMB}$ is targeted to such essential genes. From the genetic suppression data, we infer that $M M B$ is still targeted to essential genes even in the absence of Myb, and therefore does not require Myb for targeting to these gene promoters. If the vital function of Myb is to some- how induce a MMB-repressed vital gene(s) where loss of Myb was not critical for repression, then the essential activity of Myb may not require the Myb DNA-binding domain at all. In fact, recent data showed that a transgene containing a complete deletion of the DNA-binding domain of Myb is sufficient for myb-mutant viability (J. Lipsick, pers. comm.).

\section{Why are there so many $M M B$-binding sites} in the Drosophila genome?

The number of genomic binding sites for MMB far exceeded what was expected from the MMB gene regulatory network defined by the RNAi analysis. While $>80 \%$ of the $3538 \mathrm{MMB}$-binding sites were proximal to promoters, only $25 \%$ of proximal genes showed any change is expression when MMB members were depleted following RNAi treatment. Similar observations have been made for other proteins (Martone et al. 2003; Orian et al. 2003); for example, the number of genes regulated by the Myc, Max, and Mad/Mnt transcriptional network is far lower than the measured number of binding sites for these factors (Orian et al. 2003). This type of phenomenon may be a simple consequence of biological noise (Struhl 2007). It is possible that many of the complexes that are bound to sites not regulating transcription of a nearby gene are simply "junk" or vestigial in nature. A majority of such sites would have little selective advantage, or they may simply serve as a nonspecific binding pool to keep the levels of non-DNA-bound MMB low. Alternatively, these sites may play some role in other chromosome function(s) apart from gene expression. For instance, some of these "silent" MMB-binding sites may be directly modulating the selection of replication initiation sites, a point suggested by the role played by the complex in follicle cell gene amplification.

Interestingly, many of the genes that contain "silent" promoter-proximal MMB-binding sites are expressed in Kc cells and transcript levels are unaffected following removal of MMB. Perhaps, at some of these occupied sites, MMB is simply poised to respond to signals that are absent in the culture media. Prominent amongst this list are the genes encoding DNA replication proteins such as Chiffon, the ORCs, and MCMs. An evolutionarily conserved multisubunit complex in human cells that contains homologs of many of the MMB/dREAM subunits, represses cell cycle-dependent genes during quiescence (Litovchick et al. 2007). It is, of course, possible that similar control in resting cells will be found for the fly complex. This prospect would then add to the established functions of MMB in repressing differentiation-specific genes, and promoting transcription of $M$ phase genes. Extending this general point, the Kc cells are fixed in one state through their isolation in culture and well-defined passage conditions. It is possible that some of the "silent" MMB-binding sites may function in a developmental pathway that is dependent on the action of a new factor or signal not normally seen in $\mathrm{Kc}$ cells in culture. 


\section{Materials and methods}

\section{Cell culture and FACS}

Drosophila Kc cells were grown in suspension at $25^{\circ} \mathrm{C}$ in Schneider's medium (Invitrogen) supplemented with 10\% heatinactivated fetal bovine serum (Hyclone) and Antibiotic-Antimycotic solution (Invitrogen). FACS analysis was performed as described previously (Bandura et al. 2005), and data were analyzed with MultiCycle for Windows software (Phoenix Flow Systems).

\section{RNAi, immunoblot, and Northern blot}

RNAi was performed as described (Beall et al. 2004). Primer sequences used for dsRNA production are available on request. For immunoblot analysis, total protein, corresponding to $0.3 \times 10^{6}$ cells, was separated using $8 \%-12 \%$ SDS-PAGE and transferred to nitrocellulose; proteins were detected using affinity-purified polyclonal rabbit antibodies against individual complex members as described (Beall et al. 2002; Lewis et al. 2004). Mouse monoclonal anti-RBF1 and anti-RBF2 antibodies were a kind gift of N. Dyson, and were described in Frolov et al. (2001) and Stevaux et al. (2002). For determination of protein levels, blots were scanned with a Typhoon FluoroImager and signal intensities of the bands were processed using the ImageQuant program (Amersham Biosciences). Total RNA isolation and Northern blot were performed according to established procedures and are described in Beall et al. (2002) and Lewis et al. (2004).

\section{Metaphase spreads and microscopy}

Metaphase spreads were prepared as described in the Supplemental Material.

\section{Affymetrix Drosophila GeneChip}

RNAi to deplete Lin-52, Mip40, Myb, Mip120, Mip130, E2F2, both RBFs (RBF1 and RBF2), and L(3)MBT were performed in triplicate. RNAi with a nonspecific RNA derived from a $\mathrm{pBSK}^{+}$ (named $\mathrm{SK}^{+}$) was used as control (Beall et al. 2004). Total RNA was extracted from RNAi-transfected cells after $4 \mathrm{~d}$ using RNeasy Mini Kit (Qiagen). Samples were prepared and hybridized to Drosophila GeneChips (Drosgenome 1) according to Affymetrix specifications. Scans were carried on an Affymetrix GeneChip Scanner 3000 and the fluorescence intensities of scanned arrays were analyzed with Affymetrix GeneChip Operating Software (GCOS version 1.2.0). Data were analyzed as described in the Supplemental Material. The effect of RNAi was expected to lead the opposite cell regulation, and thus the positively (negatively) expressed genes under RNAi against one particular member of the MMB complex are thought to be repressed (activated) by that protein. We were interested in identifying genes regulated by arbitrary subsets of the members of the complex, and so intersections of sets of regulated genes were created; e.g., genes that were up-regulated by one subset of proteins, down-regulated by a different set, and unregulated by the remaining members of the complex (see Results). Heat maps and pie charts were generated to visualize the changes. Raw and normalized microarray expression data are available on the NCBI Gene Expression Omnibus (GEO) Web site (http://www. ncbi.nih.gov/geo) under accession code GSE8751.

\section{ChIP and $q P C R$}

ChIP was performed as reported (Andrulis et al. 2000) with some modifications detailed in the Supplemental Material. ChIP was assayed by qPCR as described in the Supplemental Material.

\section{ChIP on Drosophila tiled genomic microarrays}

In order to identify regions bound by MMB, 10-20 ng of ChIP and control DNA samples were amplified using a randomprimed PCR method, according to Affymetrix recommendations (Affymetrix Chromatin Immunoprecipitation Assay Protocol). Purified DNAs were then fragmented, TdT labeled, and hybridized to the Affymetrix Drosophila genome Tiling Array 1.0 (reverse part no. 520,054), as described previously (Manak et al. 2006). ChIP-chip data have been deposited in the GEO database under accession code GSE9087.

\section{Analysis of ChIP tiling array data}

Statistical methods used to define and analyze MMB-enriched regions are described in detail in the Supplemental Material.

\section{Acknowledgments}

We thank members of the Botchan laboratory, F. Biemar, and M.S. Levine for useful comments on the manuscript. We also thank H.B. Fraser and D.A. Nix for their helpful advice regarding data processing. This work was funded by National Institutes of Health Grant R39 CA-30490 (to M.R.B.), and in part with Federal Funds from the National Cancer Institute, National Human Genome Research Institute, National Institutes of Health, under Contract N01-CO-12400 and Grant U01 HG003147, and by Affymetrix, Inc. (to Thomas Gingeras).

\section{References}

Andrulis, E.D., Guzman, E., Doring, P., Werner, J., and Lis, J.T. 2000. High-resolution localization of Drosophila Spt5 and Spt6 at heat shock genes in vivo: Roles in promoter proximal pausing and transcription elongation. Genes \& Dev. 14: 2635-2649.

Bailey, T.L. and Elkan, C. 1994. Fitting a mixture model by expectation maximization to discover motifs in biopolymers. Proc. Int. Conf. Intell. Syst. Mol. Biol. 2: 28-36.

Bandura, J.L., Beall, E.L., Bell, M., Silver, H.R., Botchan, M.R., and Calvi, B.R. 2005. humpty dumpty is required for developmental DNA amplification and cell proliferation in Drosophila. Curr. Biol. 15: 755-759.

Beall, E.L., Manak, J.R., Zhou, S., Bell, M., Lipsick, J.S., and Botchan, M.R. 2002. Role for a Drosophila Myb-containing protein complex in site-specific DNA replication. Nature 420: 833-837.

Beall, E.L., Bell, M., Georlette, D., and Botchan, M.R. 2004. Dm-myb mutant lethality in Drosophila is dependent upon mip130: Positive and negative regulation of DNA replication. Genes \& Dev. 18: 1667-1680.

Beall, E.L., Lewis, P.W., Bell, M., Rocha, M., Jones, D.L., and Botchan, M.R. 2007. Discovery of tMAC: A Drosophila testis-specific meiotic arrest complex paralogous to Myb-Muv B. Genes \& Dev. 21: 904-919.

Carey, M. and Smale, S.T. 2000. Transcriptional regulation in eukaryotes: Concepts, strategies, and techniques. Cold Spring Harbor Laboratory Press, Cold Spring Harbor, NY.

Cayirlioglu, P., Ward, W.O., Silver Key, S.C., and Duronio, R.J. 2003. Transcriptional repressor functions of Drosophila E2F1 and E2F2 cooperate to inhibit genomic DNA synthesis in ovarian follicle cells. Mol. Cell. Biol. 23: 2123-2134.

Dimova, D.K., Stevaux, O., Frolov, M.V., and Dyson, N.J. 2003. Cell cycle-dependent and cell cycle-independent control of transcription by the Drosophila E2F/RB pathway. Genes \& 
Dev. 17: 2308-2320.

Echalier, G. 1997. Drosophila cells in culture. Academic Press, New York.

Frolov, M.V., Huen, D.S., Stevaux, O., Dimova, D., BalczarekStrang, K., Elsdon, M., and Dyson, N.J. 2001. Functional antagonism between E2F family members. Genes \& Dev. 15: 2146-2160.

Fung, S.M., Ramsay, G., and Katzen, A.L. 2002. Mutations in Drosophila myb lead to centrosome amplification and genomic instability. Development 129: 347-359.

Gagrica, S., Hauser, S., Kolfschoten, I., Osterloh, L., Agami, R., and Gaubatz, S. 2004. Inhibition of oncogenic transformation by mammalian Lin-9, a pRB-associated protein. EMBO J. 23: 4627-4638.

Goshima, G. and Vale, R.D. 2003. The roles of microtubulebased motor proteins in mitosis: Comprehensive RNAi analysis in the Drosophila S2 cell line. J. Cell Biol. 162: 1003-1016.

Goshima, G., Wollman, R., Goodwin, S.S., Zhang, N., Scholey, J.M., Vale, R.D., and Stuurman, N. 2007. Genes required for mitotic spindle assembly in Drosophila S2 cells. Science 316: 417-421.

Hochheimer, A. and Tjian, R. 2003. Diversified transcription initiation complexes expand promoter selectivity and tissuespecific gene expression. Genes \& Dev. 17: 1309-1320.

Hou, D.X., Akimaru, H., and Ishii, S. 1997. Trans-activation by the Drosophila myb gene product requires a Drosophila homologue of CBP. FEBS Lett. 413: 60-64.

Jackson, J., Ramsay, G., Sharkov, N.V., Lium, E., and Katzen, A.L. 2001. The role of transcriptional activation in the function of the Drosophila myb gene. Blood Cells Mol. Dis. 27: 446-455.

Katzen, A.L., Kornberg, T.B., and Bishop, J.M. 1985. Isolation of the proto-oncogene c-myb from $D$. melanogaster. Cell 41: 449-456.

Katzen, A.L., Jackson, J., Harmon, B.P., Fung, S.M., Ramsay, G., and Bishop, J.M. 1998. Drosophila myb is required for the G2/M transition and maintenance of diploidy. Genes \& Dev. 12: $831-843$.

Korenjak, M., Taylor-Harding, B., Binne, U.K., Satterlee, J.S., Stevaux, O., Aasland, R., White-Cooper, H., Dyson, N., and Brehm, A. 2004. Native E2F/RBF complexes contain Mybinteracting proteins and repress transcription of developmentally controlled E2F target genes. Cell 119: 181-193.

Lee, L.A. and Orr-Weaver, T.L. 2003. Regulation of cell cycles in Drosophila development: Intrinsic and extrinsic cues. Annu. Rev. Genet. 37: 545-578.

Levine, M. and Tjian, R. 2003. Transcription regulation and animal diversity. Nature 424: 147-151.

Lewis, P.W., Beall, E.L., Fleischer, T.C., Georlette, D., Link, A.J., and Botchan, M.R. 2004. Identification of a Drosophila MybE2F2/RBF transcriptional repressor complex. Genes \& Dev. 18: 2929-2940.

Litovchick, L., Sadasivam, S., Florens, L., Zhu, X., Swanson, S.K., Velmurugan, S., Chen, R., Washburn, M.P., Liu, X.S. and DeCaprio, J.A. 2007. Evolutionarily conserved multisubunit RBL2/p130 and E2F4 protein complex represses human cell cycle-dependent genes in quiescence. Mol. Cell 26: 539_ 551

Manak, J.R., Mitiku, N., and Lipsick, J.S. 2002. Mutation of the Drosophila homologue of the Myb protooncogene causes genomic instability. Proc. Nat1. Acad. Sci. 99: 7438-7443.

Manak, J.R., Dike, S., Sementchenko, V., Kapranov, P., Biemar, F., Long, J., Cheng, J., Bell, I., Ghosh, S., Piccolboni, A., et al 2006. Biological function of unannotated transcription during the early development of Drosophila melanogaster. Nat.
Genet. 38: 1151-1158.

Manak, J.R., Wen, H., Tran, V., Andrejka, L., and Lipsick, J.S. 2007. Loss of Drosophila Myb interrupts the progression of chromosome condensation. Nat. Cell Biol. 9: 581-587.

Martone, R., Euskirchen, G., Bertone, P., Hartman, S., Royce, T.E., Luscombe, N.M., Rinn, J.L., Nelson, F.K., Miller, P., Gerstein, M., et al. 2003. Distribution of NF-кB-binding sites across human chromosome 22. Proc. Nat1. Acad. Sci. 100: $12247-12252$.

Okada, M., Akimaru, H., Hou, D.X., Takahashi, T., and Ishii, S. 2002. Myb controls G(2)/M progression by inducing cyclin B expression in the Drosophila eye imaginal disc. EMBO J. 21: 675-684.

Orian, A., van Steensel, B., Delrow, J., Bussemaker, H.J., Li, L., Sawado, T., Williams, E., Loo, L.W., Cowley, S.M., Yost, C., et al. 2003. Genomic binding by the Drosophila Myc, Max, $\mathrm{Mad} / \mathrm{Mnt}$ transcription factor network. Genes \& Dev. 17: $1101-1114$.

Osterloh, L., von Eyss, B., Schmit, F., Rein, L., Hubner, D., Samans, B., Hauser, S., and Gaubatz, S. 2007. The human synMuv-like protein LIN-9 is required for transcription of G2/M genes and for entry into mitosis. EMBO J. 26: 144-157.

Pilkinton, M., Sandoval, R., Song, J., Ness, S.A., and Colamonici, O.R. 2007. Mip/LIN-9 regulates the expression of B-MYB, and the induction of cyclin a, cyclin B and CDK1. J. Biol. Chem. 282: 168-175.

Ptashne, M. 2007. On the use of the word 'epigenetic.' Curr. Biol. 17: R233-R236. doi: 10.1016/j.cub.2007.02.030.

Ren, B., Cam, H., Takahashi, Y., Volkert, T., Terragni, J., Young, R.A., and Dynlacht, B.D. 2002. E2F integrates cell cycle progression with DNA repair, replication, and $\mathrm{G}(2) / \mathrm{M}$ checkpoints. Genes \& Dev. 16: 245-256.

Small, S., Kraut, R., Hoey, T., Warrior, R., and Levine, M. 1991. Transcriptional regulation of a pair-rule stripe in Drosophila. Genes \& Dev. 5: 827-839.

Stevaux, O., Dimova, D., Frolov, M.V., Taylor-Harding, B., Morris, E., and Dyson, N. 2002. Distinct mechanisms of E2F regulation by Drosophila RBF1 and RBF2. EMBO J. 21: 49274937.

Stevaux, O., Dimova, D.K., Ji, J.Y., Moon, N.S., Frolov, M.V., and Dyson, N.J. 2005. Retinoblastoma family 2 is required in vivo for the tissue-specific repression of $\mathrm{dE} 2 \mathrm{~F} 2$ target genes. Cell Cycle 4: 1272-1280.

Struhl, K. 2007. Transcriptional noise and the fidelity of initiation by RNA polymerase II. Nat. Struct. Mol. Biol. 14: 103105.

Thanos, D. and Maniatis, T. 1995a. Identification of the rel family members required for virus induction of the human $\beta$ interferon gene. Mol. Cell. Biol. 15: 152-164.

Thanos, D. and Maniatis, T. 1995b. Virus induction of human IFN $\beta$ gene expression requires the assembly of an enhanceosome. Cell 83: 1091-1100.

Trojer, P., Li, G., Sims III, R.J., Vaquero, A., Kalakonda, N., Boccuni, P., Lee, D., Erdjument-Bromage, H., Tempst, P., Nimer, S.D., et al. 2007. L3MBTL1, a histone-methylationdependent chromatin lock. Cell 129: 915-928. 


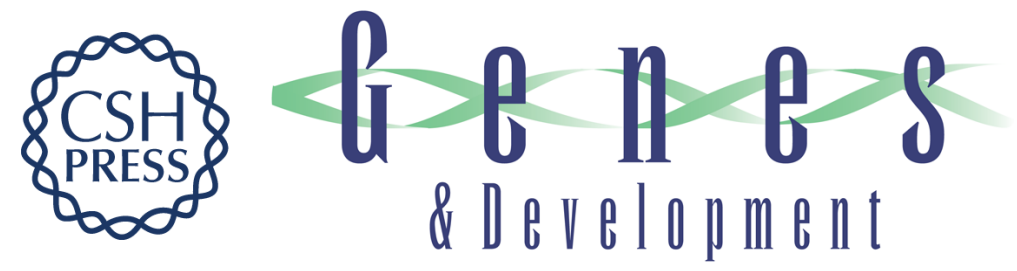

\section{Genomic profiling and expression studies reveal both positive and negative activities for the Drosophila Myb-MuvB/dREAM complex in proliferating cells}

Daphne Georlette, Soyeon Ahn, David M. MacAlpine, et al.

Genes Dev. 2007, 21: originally published online October 31, 2007

Access the most recent version at doi:10.1101/gad.1600107

Supplemental Material

References

License

Email Alerting

Service
http://genesdev.cshlp.org/content/suppl/2007/10/31/gad.1600107.DC1

This article cites 40 articles, 21 of which can be accessed free at: http://genesdev.cshlp.org/content/21/22/2880.full.html\#ref-list-1

Receive free email alerts when new articles cite this article - sign up in the box at the top right corner of the article or click here.

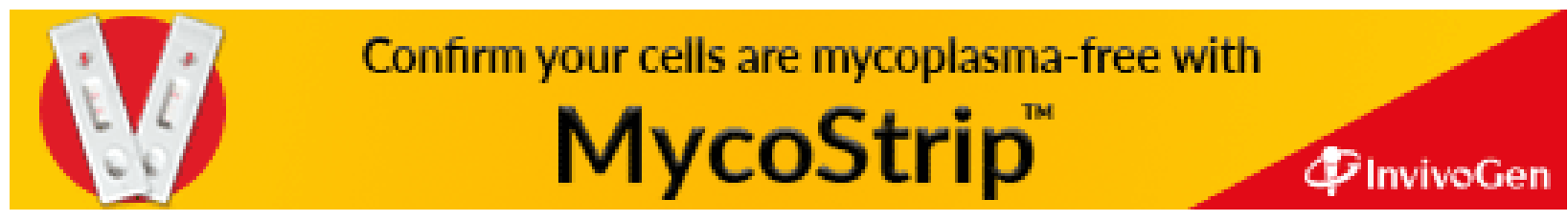

